\title{
BMA
}

\section{Alcohol, drugs and the workplace - The role of medical professionals}

A briefing from the BMA Occupational Medicine Committee

2nd Edition, July 2016

$$
\text { ติ }
$$




\section{Editorial board}

A publication from the BMA Occupational Medicine Committee (OMC).

Authors Dr Paul Nicholson (Chair)

Dr Grant Mayho

Dr Chris Sharp

Editorial Secretariat Hugh Townsend

George Roycroft

\section{Occupational Medicine Committee}

This report was prepared under the auspices of the Occupational Medicine Committee of the British Medical Association, whose membership for 2015/2016 was as follows:

Members Elected or Appointed by the BMA Representative Body

Dr Paul Nicholson (Chair)

Dr Susan Robson

Dr Nigel Wilson

Members Elected or Appointed by BMA Council

Dr Chris Sharp

Dr Grant Mayho

Dr David Fox

\section{Otherwise Elected or Appointed}

Dr lan Murphy - Joint representative Faculty of Occupational Medicine and Society of Occupational Medicine Dr Mark Weir - BMA Council member representing doctors in occupational medicine

Dr Ragadeepika Siddabathuni - member representing trainees in occupational medicine

The Occupational Medicine Committee, a representational committee of the BMA, considers and report on matters affecting the health, safety and welfare of persons at work and the practice of medicine in industry and allied occupations. The committee is charged with advising the Association on the implementation of health, safety and welfare legislation as it affects its members and their working environment. 


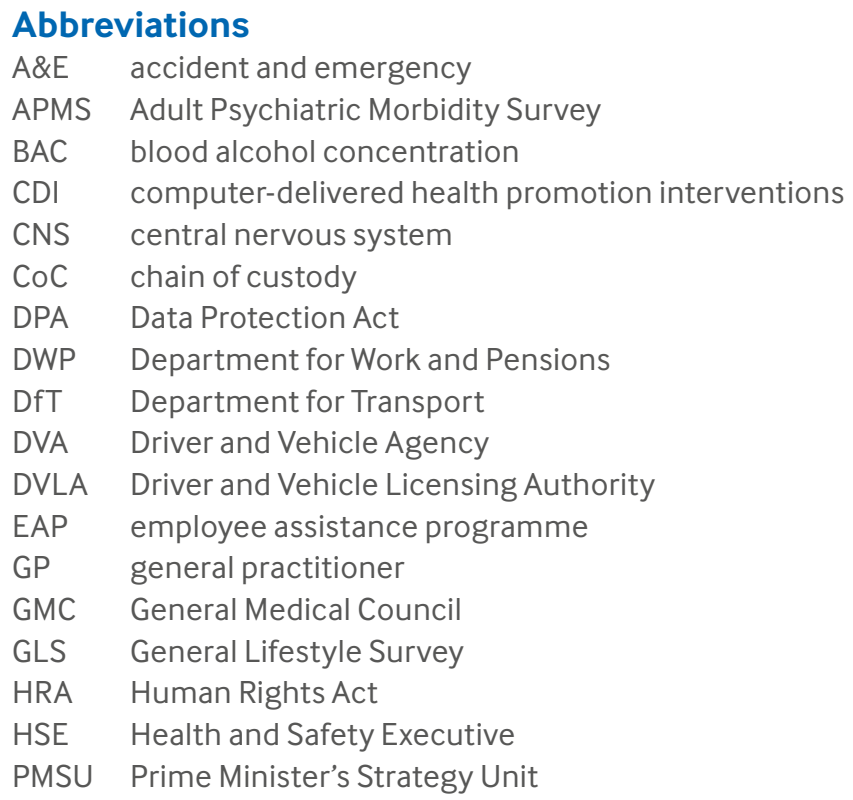

\section{A note on terminology}

Various terms are used to describe different patterns of use of alcohol and illicit drugs. These can have similar or overlapping meanings, and can vary, from terms with no standard definition to diagnostic terms.

For the purposes of this guidance, the term 'use' (self-administration of a psychoactive substance) is predominantly used. Other terms are used in this guidance where they refer to a specific pattern of alcohol or illicit drug use, and are defined accordingly.

A unit of alcohol corresponds to 7.9 grams $(\mathrm{g})$ or 10 millilitres $(\mathrm{ml})$ of ethanol. This term is used to provide a measure of the amount of alcohol in a drink. Different methods are used to define standard measurements internationally none of which correspond to the UK unit.

A short Glossary is provided below using definitions within the Lexicon of alcohol and drug terms published by the World Health Organization but we would suggest using that lexicon or the glossaries provided in 'Drugs of dependence - the role of medical professionals' (BMA Board of Science, January 2013) and 'Alcohol misuse: tackling the UK epidemic' (BMA Board of Science, February 2008) for fuller definitions of these terms.

\section{Abstinence}

Refraining from drug use or from drinking alcohol. Those who practise abstinence from alcohol are termed "abstainers", "total abstainers". The term "current abstainer", often used in population surveys, is usually defined as a person who has not consumed alcohol in the preceding 12 months.

\section{Addiction}

Repeated use of a psychoactive substance or substances, to the extent that the user (referred to as an addict) is periodically or chronically intoxicated, shows a compulsion to take the preferred substance (or substances), has great difficulty in voluntarily ceasing or modifying substance use, and exhibits determination to obtain psychoactive substances by almost any means. The term is often used interchangeably with dependence. Addiction is not a diagnostic term in ICD-10, but continues to be widely employed by professionals and the general public alike.

\section{Chain of custody}

The process for managing the collection, handling, storage and testing of biological samples, to prevent contamination or interference. 


\section{Controlled substances}

Psychoactive substances and their precursors, the distribution of which is forbidden by law or limited to medical and pharmaceutical channels. The substances subject to this control differ between countries. The term is often used to refer to psychoactive drugs and precursors covered by international drug conventions. At international and national levels, controlled drugs are commonly classified according to a hierarchy of schedules, reflecting different degrees of restriction of availability.

\section{Dependence}

As a general term, dependence is the state of needing or depending on something or someone for support or to function or survive. As applied to alcohol and other drugs, the term includes psychological and physiological aspects. Psychological dependence involves impaired control over drug use and a need (craving) for repeated doses of the drug, to feel good or avoid feeling bad. Physiological or physical dependence is associated with tolerance, where increased doses of the drug are required to produce the effects originally produced by lower doses, and development of withdrawal syndrome when the drug is withdrawn. The term is often used interchangeably with addiction.

\section{Detoxification}

The process by which an individual is withdrawn from the effects of a psychoactive substance. The aim is to reverse or reduce dependence on and tolerance to a psychoactive drug. As a clinical procedure, the withdrawal process is carried out in a safe and effective manner, such that withdrawal symptoms are minimised.

\section{Drug}

In medicine, it refers to any substance with the potential to prevent or cure disease or enhance physical or mental welfare. In pharmacology it refers to any chemical agent that alters the biochemical or physiological processes of tissues or organisms. Hence, a drug is a substance that is, or could be, listed in a pharmacopoeia. In common usage, the term often refers specifically to psychoactive drugs, and often, even more specifically, to illicit drugs, of which there is non-medical use in addition to any medical use. Professional formulations (eg 'alcohol and other drugs') often seek to make the point that caffeine, tobacco, alcohol and other substances in common non-medical use are also drugs in the sense of being taken, at least in part, for their psychoactive effects.

\section{Illicit drug}

A psychoactive substance, the possession, production, sale or use of which is prohibited. Strictly speaking, it is not the drug that is illicit, but its possession, production, sale or use in particular circumstances in a given jurisdiction.

\section{Illicit drug use}

In this document the term is used to refer to the use of illicit drugs and the illicit use of legal drugs.

\section{Intoxication}

A transient condition that follows the administration of alcohol or other psychoactive substance and results in disturbances in level of consciousness, cognition, perception, affect or behaviour, or other psycho-physiological functions and responses'. The term is most commonly used with regard to alcohol use; its equivalent in everyday speech is "drunkenness".

\section{Medical review officers}

Physicians who have had specific training to interpret drug test results.

\section{Occupational physician}

The Faculty of Occupational Medicine (FOM) defines an occupational physician as a doctor who possesses a qualification in occupational medicine recognised by the FOM and has particular competencies, acquired through postgraduate training and experience and who maintains these through ongoing continuing professional development, and annual appraisal that addresses his/her practice in occupational medicine.

\section{Presenteeism}

Attending work whilst impaired by illness or other conditions. This is thought to cause more workplace productivity loss than absenteeism. 


\section{Post-offer health assessment}

Post-offer health assessments are undertaken after a person has been offered a job and before commencing duties, usually in safety critical work, to ensure that any health condition from which the individual suffers does not present a hazard to themselves or to other persons, e.g. for airline pilots, air traffic control officers, armed forces personnel, seafarers, divers, licensed goods vehicle drivers, etc. In some of these cases, assessment of medical fitness for work may be a statutory requirement.

\section{Problem drug use}

There are varying definitions for problem drug use. In its broadest sense, according to the United Nations Office on Drugs and Crime (UNODC), problem drug use is used to describe individuals who inject drugs and/or are considered dependent, facing serious social and health consequences as a result. For statistical purposes, the definitions and methods of calculation differ from country to country. The European Monitoring Centre for Drugs and Drug Addiction (EMCDDA) defines problem drug use as 'injecting drug use or long duration/regular use of opioids, cocaine and/or amphetamines'.

\section{Psychoactive substance use disorders}

A shortened version of the term used in ICD-10 - mental and behavioural disorders associated with psychoactive Substance use. The term encompasses acute intoxication, harmful use, dependence syndrome, withdrawal state, withdrawal state with delirium, psychotic disorder, and amnesic syndrome. For a particular substance, these conditions may be grouped together as, for example, cannabis use disorders, stimulant use disorders. Psychoactive substance use disorders are defined as being of clinical relevance; the term 'psychoactive substance use problems' is a broader one, which includes conditions and events not necessarily of clinical relevance.

\section{Safety-critical roles}

Jobs that can present risk to the individual concerned or to others should the employee be impaired mentally or physically e.g. vocational driving, working on, or in the vicinity of, electrical and mechanical systems, working at height or in confined spaces, managing safety-critical systems at major-hazard sites.

\section{Use (alcohol or drug)}

Self-administration of a psychoactive substance. This term has been used throughout this guidance rather than drug abuse or drug misuse, as it is non-judgemental. 


\section{Contents}

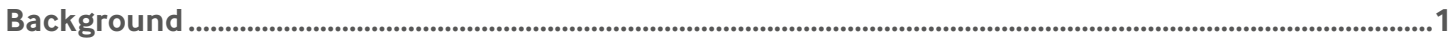

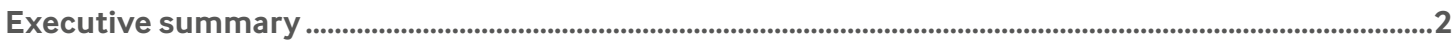

Chapter 1 - Introduction ...........................................................................................................................................................

1.1 Substance use as an issue in the workplace ........................................................................................................ 3

1.2 The legal framework for alcohol and illicit drugs and the workplace ............................................................... 4

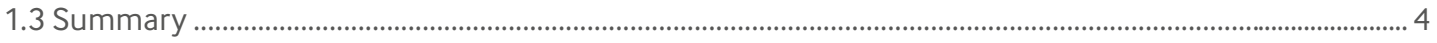

Chapter 2 - The scale of the problem .................................................................................................

2.1 Prevalence and patterns of use in people of working age ........................................................................................ 5

2.2 Prevalence and patterns of use among the employed................................................................................................... 6

2.3 International perspective ....................................................................................................................................................... 8

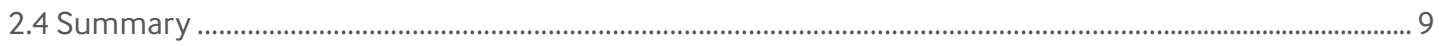

Chapter 3 - The burden of the problem ..................................................................................................... 10

3.1 Physical, psychological and social burden to workers ...................................................................................10

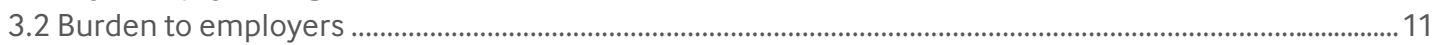

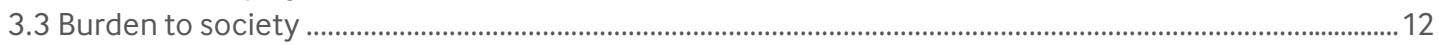

3.4 International Perspective ................................................................................................................................12

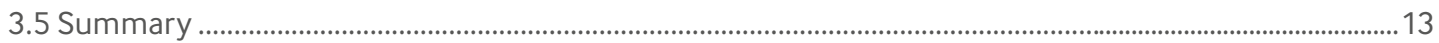

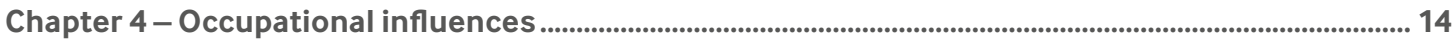

4.1 Occupations at risk for alcohol use ....................................................................................................................

4.2 Occupations at risk for illicit drug use .............................................................................................................. 14

4.3 International perspective ………………………………………………………………………………..... 14

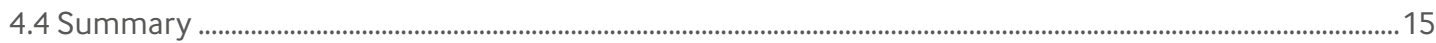

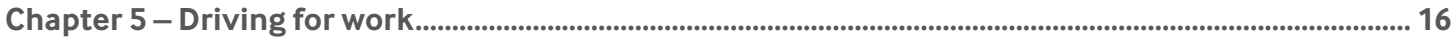

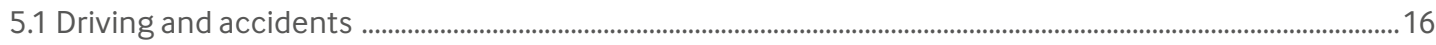

5.2 Medical standards for driving licences ............................................................................................................16

5.3 Driving, declaration and disclosure .............................................................................................................. 16

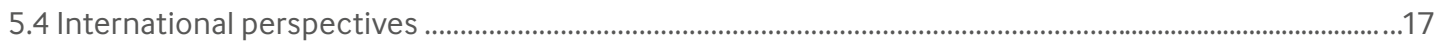

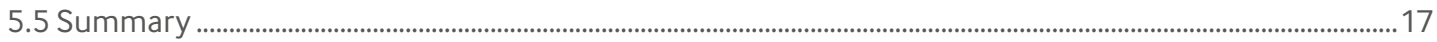

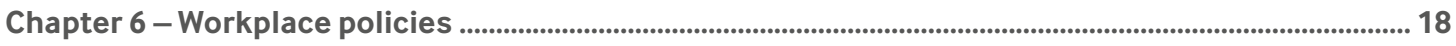

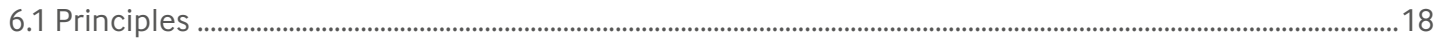

6.2 Policy framework .......................................................................................................................................................

6.3 International perspective .............................................................................................................................................19

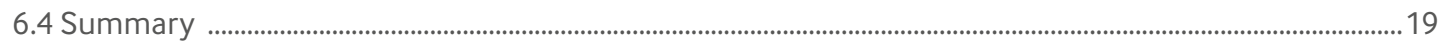

Chapter 7 - Workplace screening and testing ............................................................................................................. 20

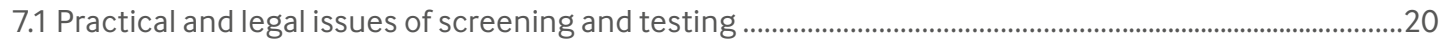

7.2 Consent and confidentiality .................................................................................................................................20

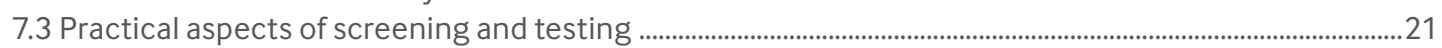

7.4 International perspectives ................................................................................................................................................22

7.5 Summary ....................................................................................................................................................................22

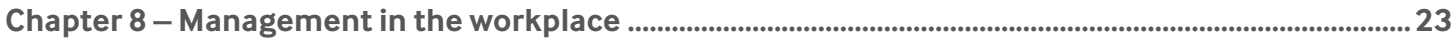

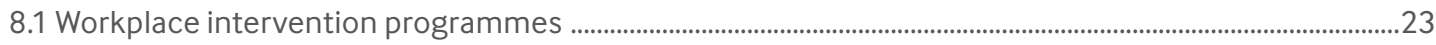

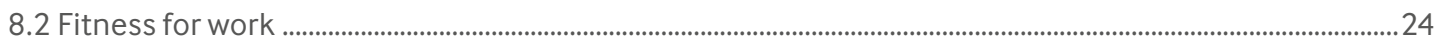

8.3 International perspectives ..............................................................................................................................................2

8.4 Summary .....................................................................................................................................................................25

Chapter 9 - Occupational health support for job applicants .......................................................................... 26

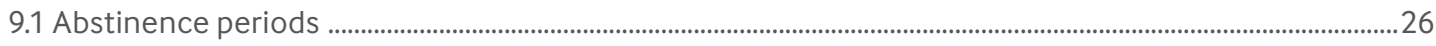

9.2 Post-offer health assessments ...............................................................................................................................2

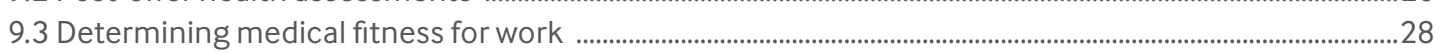

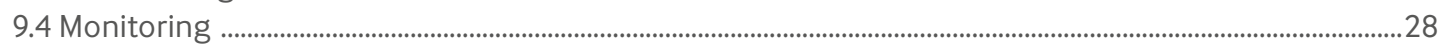

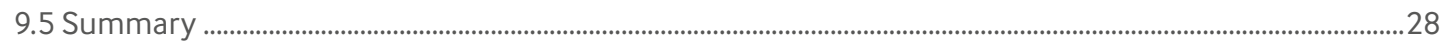

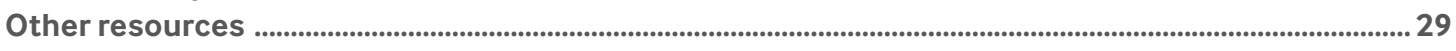

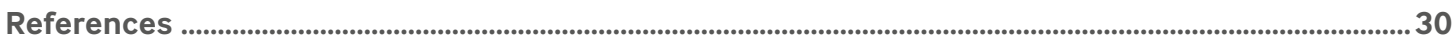




\section{Background}

There are many different types of psychoactive drugs in common use that have the potential to cause harm to health and wellbeing. The extent of harm depends on the type of drug, how it is used, and the social context within which it is used. Through its Board of Science, the BMA has developed substantial policy on the use of alcohol, which has resulted in several publications. In January 2013, the Board published 'Drugs of Dependence - the role of medical professionals', which aims to encourage debate on the most effective approach to preventing and reducing the harms associated with illicit use of drugs, how to make best use of illicit-drug control policies, and examines the role of the medical profession in relation to illicit drug use.

This guidance was first published in 2014 and supplements the work published by the Board of Science on alcohol and the use of illicit drugs, and aims to provide practical advice to medical professionals to help them understand and support working patients and employers to address the use of alcohol and illicit drugs by people who work. This second edition was updated and chapter 9 added in response to a Department for Work and Pensions review into how best to support benefit claimants with addictions and potentially treatable conditions back into work.

While aimed primarily at medical professionals, this booklet may also assist other health care professionals, managers, human resources specialists and employee representatives.

While employers and workers may turn to occupational health professionals for advice and support where such support exists, only about one in seven of the workforce has access to a qualified occupational physician. ${ }^{1}$ Many workers will rely on their general practitioner (GP) or hospital specialist for advice relating to fitness for work and employers may request reports from these doctors. For these reasons it is important that all doctors understand employment aspects of the use of alcohol and illicit drugs.

Medical professionals should be aware that some prescribed medication may cause side effects that can impair a patient's performance at work. This is outside the scope of this guidance. Nevertheless medical professionals should always consider a patient's occupation when prescribing medication that might affect their fitness for specific types of occupational activity, particularly those patients who drive, operate machinery, or work at heights.

Doctors may also work as managers or as employers. While this guidance does not aim to act as guidance for employers, some content (eg legal background and workplace policies) may prove helpful to doctors who have such responsibilities.

Core guidance from the General Medical Council (GMC) set out in Outcomes for graduates (Tomorrow's Doctors) ${ }^{2}$ maintains that medical school graduates need to be able to "identify appropriate strategies for managing patients with dependence issues and other demonstrations of self-harm'. 


\section{Executive summary}

Alcohol use increases the risk of problems in the workplace, such as absenteeism, presenteeism, and inappropriate behaviour. Use of alcohol or illicit drugs can impair a person's performance at work through poor decision making and impaired reaction times causing lost productivity, inferior goods/services, errors and accidents.

- It is evident that alcohol and illicit drug use is prevalent in those who are in work and as such is a significant issue for the workplace and is a growing concern for employers. Individuals in employment are more likely to drink frequently compared to those who are unemployed. Individuals in managerial and professional occupations drink more frequently than those in routine and manual occupations

- Certain working situations and conditions are associated with use of alcohol and illicit drugs (ie shift or night work, travel away from home, working remotely, business meals, poor communications and job stress, etc). There are many factors within the workplace culture that present an increased risk for the use of substances including availability, work/peer-group pressures, lack of supervision, physical danger and interface with a demanding or aggressive public. International evidence also indicates that longer working hours are significantly associated with higher rates of alcohol use and related problems

- Use and possession of illicit drugs falls under several criminal laws. Employers have a general duty under the Health and Safety at Work etc Act 1974 to ensure, as far as is reasonably practicable, the health, safety and welfare at work of their employees and others affected by their work activities

- Workplaces provide venues and captive audiences for health education and opportunities to identify individuals who have problems with alcohol and illicit drug use. Medical professionals who support workplaces are well placed to offer health education for workers, and training for managers and supervisors about how to recognise and deal with alcohol and illicit drug use issues

- Alcohol and illicit drug use is associated with a range of physical, psychological and social harms, which inflict an economic burden on employers, governments and society. The burden that alcohol and illicit drug use places on organisations makes it, at the very least, advisable for employers to have an alcohol and drug (substance) use policy. These policies are more successful when conceived as a component of health and welfare policy rather than primarily a disciplinary matter

- Where a medical professional is asked for advice by an employer they must establish the capacity in which they are being asked for advice and make clear to patients their professional role. Medical professionals should seek to understand the employer's alcohol and drug use policy (eg does it apply to all employees or just those in safety critical roles? What support is available to employees?)

- Managers and supervisors should be trained to recognise the signs of problems with alcohol and illicit drug use. They should know what to do if they suspect an employee has a problem or if they are approached by an employee who declares a problem and arrange a referral to occupational health services

- In supporting people with a past or current alcohol or drug problem back into work health professionals must avoid the application of arbitrary abstinence periods, except where they are legally mandated eg for driving

- Health professionals can be very influential in addressing employers' concerns about risks and challenging stigma and negative stereotypes 


\section{Chapter 1 - Introduction}

The scale of alcohol and illicit drug use in the UK represents a significant cause of medical, psychological and social harm. Both are associated with preventable premature ill health and mortality - in 2014 there were 8,697 alcohol-related deaths registered in the UK. ${ }^{3}$ While alcohol-related death rates have fallen since 2008, the rate in 2014 exceeds that observed in 1994. ${ }^{3}$ 2,248 drug-related deaths were registered in England and Wales in 2014 with record high numbers for both genders. ${ }^{4}$ The true figures are likely to be higher; drug and alcohol misuse contributing to more deaths than those identified by certification.

The harms associated with the use of these psychoactive substances extend beyond the direct impact on the individual user to the impact on children, families, communities and society as a whole. These harms are associated with substantial economic and social costs that can be divided into four broad categories:

- healthcare

- crime, disorder and anti-social behaviour

- workplace

- impact on family and social networks

This guidance focuses on the workplace. The importance of the workplace setting in preventing and managing the use of alcohol and illicit drugs reflects the fact that almost two-thirds of the UK population is of working age. ${ }^{5}$ As around three quarters of this age group are in employment ${ }^{6}$ the impact of the use of alcohol and illicit drugs in the workplace is substantial. The impact includes lower productivity through sickness-related absence, inappropriate behaviour, accidents and poor performance, as well as shorter working lives. The workplace setting also provides venues and captive audiences for health education and opportunities to identify individuals with substance use problems. Medical professionals who support workplaces are well placed to offer health education for workers and training for managers and supervisors about how to recognise and deal with substance use problems.

\subsection{Substance use as an issue in the workplace}

Alcohol and illicit drug use is a concern when it affects the performance of a person in the workplace, or when it puts at risk the safety of that individual, other workers or the general public. Contrary to popular belief, the majority of people who have an alcohol use problem are in work. ${ }^{7}$ In the workplace, alcohol use can increase the risk of problems such as absenteeism, presenteeism and inappropriate behaviour. Workplaces and certain jobs, themselves, can also increase the risk of alcohol use disorders and alcohol dependence (see Chapter 4).

The use of illicit drugs can be a serious problem not only for the user but also for the business where they work. The possession of some drugs is illegal, exposing the user to the risk of criminal charges as well as causing harmful effects to their health. Employers could be breaking the law if they knowingly allow drugrelated activities in the workplace and fail to act. ${ }^{8}$

Given the levels of consumption in society, it is not surprising that four out of ten UK employers who responded to a survey identified alcohol consumption as a significant or very significant cause of employee absence and lost productivity. A third of organisations reported that drug misuse had a similarly negative effect in the workplace. ${ }^{9}$ 


\subsection{The legal framework for alcohol and illicit drugs and the workplace}

The principal UK legislation for controlling the use of illicit drugs is the Misuse of Drugs Act 1971. The Act makes the production, supply and possession of these controlled drugs unlawful except in certain specified circumstances (eg when they have been prescribed by a doctor). If an employer knowingly permits the production, supply or possession of any controlled drugs, or the smoking of cannabis to occur on their premises they could be committing an offence. ${ }^{8}$

Employers have a general duty under the Health and Safety at Work etc Act 1974 to ensure, as far as is reasonably practicable, the health, safety and welfare at work of their employees and others affected by their work activities. Employers also have a duty under the Management of Health and Safety at Work Regulations 1999 to assess the risks to the health and safety of their employees. An employer could be prosecuted if they knowingly allow an employee to work under the influence of a drug where his or her behaviour places that employee or others at risk. Employees are also required to take reasonable care of themselves and others who could be affected by what they do at work. ${ }^{8}$

The Transport and Works Act 1992 makes it a criminal offence for some workers to be unfit through alcohol and/or drugs while working on railways, tramways and other guided transport systems. The operators of the transport system would also be guilty of an offence unless they had demonstrated due diligence in attempting to prevent such an offence being committed. The Railways and Transport Safety Act 2003 extends these requirements to aviation and maritime workers, making it a criminal offence for these workers to have impaired ability to function because of alcohol and/or drugs or if the proportion of alcohol in breath, blood or urine exceeds the prescribed limit established by the Act.

The Road Traffic Act 1988 makes it clear that anyone who is unfit to drive through alcohol or drugs and is in charge of a motor vehicle, or who drives or attempts to drive a motor vehicle on a road or other public place, is guilty of an offence. This Act specifies that it is an offence to drive or be in charge of a motor vehicle with an alcohol concentration above a prescribed limit. The Drug Driving (Specified Limits) (England \& Wales) Regulations 2014, and subsequent amendment, 2015 likewise makes it a criminal offence to drive or be in charge of a vehicle with specified blood drug concentrations above prescribed limits.

The Work in Compressed Air Regulations 1996 place duties on compressed air contractors to ensure that no person works in compressed air where the compressed air contractor has reason to believe said person to be under the influence of alcohol or a drug to such an extent that his capacity to carry out any task for which he is responsible is impaired. These Regulations also state that no person shall consume alcohol or possess any alcoholic drink when in compressed air. The compressed air contractor needs to establish appropriate management procedures, supported by site supervisors and lock attendants, to prevent access to compressed air working of anyone considered to be under the influence of alcohol or drugs, and to prevent the taking of alcohol into compressed air.

\subsection{Summary}

- The impact of alcohol and illicit drug use is often noticeable in the workplace, where it is associated with an increased risk of problems such as absenteeism, presenteeism, accidents, poor performance and inappropriate behaviour.

- Workplaces provide venues and captive audiences for health education and opportunities to identify individuals who have problems with alcohol and drug use. Medical professionals who support workplaces are well placed to offer health education for workers and training for managers and supervisors about how to recognise and deal with substance use problems.

- The use of alcohol and drugs falls under several different areas of legislation. Individuals face potential criminal prosecution. Employers have a general duty under the Health and Safety at Work etc Act 1974 to ensure, as far as is reasonably practicable, the health, safety and welfare at work of their employees and others affected by their work activities. 


\section{Chapter 2 - The scale of the problem}

In establishing the scale of the problem at a workplace level, it is first important to consider the levels of alcohol and illicit drug use at a population level. This reflects the strong relationship between the total use at a population level, and the level of use in sub-populations (eg the working population). The prevalence of alcohol and illicit drug use in the general population varies temporally, demographically, and geographically.

Despite a slight overall decline in recent years, alcohol consumption in the UK remains at a high level. Since 1990, the average amount drunk each year by adults (aged over 15) in the UK increased from 9.8 litres of pure alcohol per head to a peak of 11.5 litres in 2004, and subsequently declined to 9.8 litres in $2012 .{ }^{10}$ Survey data have found that a significant proportion of the UK adult population consume alcohol above recommended amounts. ${ }^{11}$

Recent Crime Surveys for England and Wales show that around one in 12 adults aged 16 to 59 had taken an illicit drug in the last year (around 2.8 million people in 2014/15). The trend since 2009/10 has fluctuated between eight and nine per cent, but has remained relatively flat, so levels of drug use are generally stable. This follows a period of gradually decreasing proportions from a peak in 2003/04. Prior to 2003/04, the proportion remained broadly flat at around 12 per cent. ${ }^{12}$

It is difficult to quantify the scale of substance use accurately in working populations, there being little community based research designed to establish the prevalence of, and characteristics associated with, alcohol and illicit drug use among workers. ${ }^{13}$ The following provides an indication of the scale of substance use in working populations through data on prevalence and patterns of use in people of working age and in employment, as well as comparable international data.

\subsection{Prevalence and patterns of use in people of working age}

\section{Alcohol}

The General Lifestyle Survey (GLS) provided various measures of alcohol consumption among families and people living in private households in Great Britain. GLS data was based on self-reporting to a large extent and may underestimate alcohol/drug burdens. The last GLS data to be published showed considerable variation in drinking patterns between age groups:

- Average levels of weekly alcohol consumption were about a third lower among adults aged 65 and over than they were in the other age groups. Average consumption was 11.1 units a week in the 16 to 24 age group, 12.2 units in the 25 to 44 age group and 13.1 units in the 45 to 64 age group. ${ }^{11}$

- The age group with the highest proportion of people not drinking at all in the last week was the 16 to 24 group (50\%). The proportion of adults who drank every day increased with each age group; one per cent of the 16 to 24 age group had drunk every day during the previous week, compared to four per cent in the 25 to 44 group, nine per cent in the 45 to 64 age group, and 13 per cent in the 65 and over age group. ${ }^{14}$

- 2.5 million people drink more than 14 units of alcohol on their heaviest drinking day. ${ }^{15}$

- Young people aged 16 to 24 years old were less likely to have consumed alcohol in the previous week, compared with those aged 45 to 64 (48\% vs 66\%), however, young drinkers were more likely than any other age group to consume more than the weekly recommended limit in one day $(17 \%$ vs $2 \%$ of those aged 65 and over). ${ }^{15}$

Key conclusions from these data are that those in the youngest and oldest age groups (16 to 24 and 65 and over) are less likely than those in the other age groups to report drinking alcohol during the previous week; among men and women, those across the working age population are much more likely to drink enough to risk suffering physical or psychological harm.

Other data provide some information on other significant patterns of alcohol consumption. According to the 2007 Adult Psychiatric Morbidity Survey (APMS) for England, the highest levels of alcohol dependencee were identified in men between the ages of 25 and 34 (16.8\%), and women between the ages of 16 and $24(9.8 \%)^{16}$ 


\section{Illicit drugs}

According to the 2014/15 Crime Survey for England and Wales:

Around 1 in 12 adults aged 16 to 59 had taken an illicit drug in the last year.

Around 1 in 5 young adults aged 16 to 24 had taken an illicit drug in the last year.

Around 1 in 20 adults aged 16 to 59 had taken an illicit drug in the last month

Around one in ten young adults aged 16 to 24 had taken an illicit drug in the last month

Just over one-third of adults aged 16 to 59 had taken drugs at some point during their lifetime. ${ }^{12}$

Data from various surveys provide a more detailed picture of illicit drug use in the UK:

- cannabis continues to be the most commonly reported drug across all recall periods, with cocaine and ecstasy the next most popular drugs in terms of recent and current use

- younger people are more likely to take drugs than older people

- men are more likely to report drug use than women, across all age groups

- people living in urban areas reported higher levels of drug use than those living in rural areas

- higher levels of drug use are associated with increased frequency of visits to pubs, bars and nightclubs

- the extent of frequent use varies between drugs, with cannabis users most likely to report frequent use (more than once a month in the past year)

- those who consume alcohol frequently have higher levels of recent drug use than those who consumed alcohol less frequently. ${ }^{12,17,18}$

While these data show that a smaller proportion of the UK working age population use illicit drugs compared to alcohol, it is clear that illicit drug use is a significant problem - approximately three million people (aged 16 to 59) have used illicit drugs recently, and over one million are current users.

\subsection{Prevalence and patterns of use among the employed}

\section{Alcohol}

The link between alcohol consumption and socio-economic factors is an important consideration. According to the $2011 \mathrm{GLS}$, men and women aged 16 to 64 and in employment were more likely to have consumed alcohol in the previous week compared to individuals who were unemployed and who were economically inactive. ${ }^{14}$ Similar patterns were found in relation to drinking on five or more days in the previous week, drinking heavily and binge drinking.

Among adults working full time, drinking behaviour was related directly to earnings from employment and household income (see Table 1). ${ }^{14,15}$ Almost four out of every five high earners ( $€ 40,000$ or more) had drunk alcohol in the last week and alcohol consumption generally falls as income falls. Almost three in 10 lowest earners classed themselves as teetotal, compared with less than one in 10 for the highest earners. The difference could be due to the characteristics of those in each group eg the higher income bands have a smaller amount of those aged 16 to 24 , who are less likely to have drunk in the previous week. 
Table 1: Percentage of those who had drank at least 5 days in the last week, by income, 2014, Great Britain

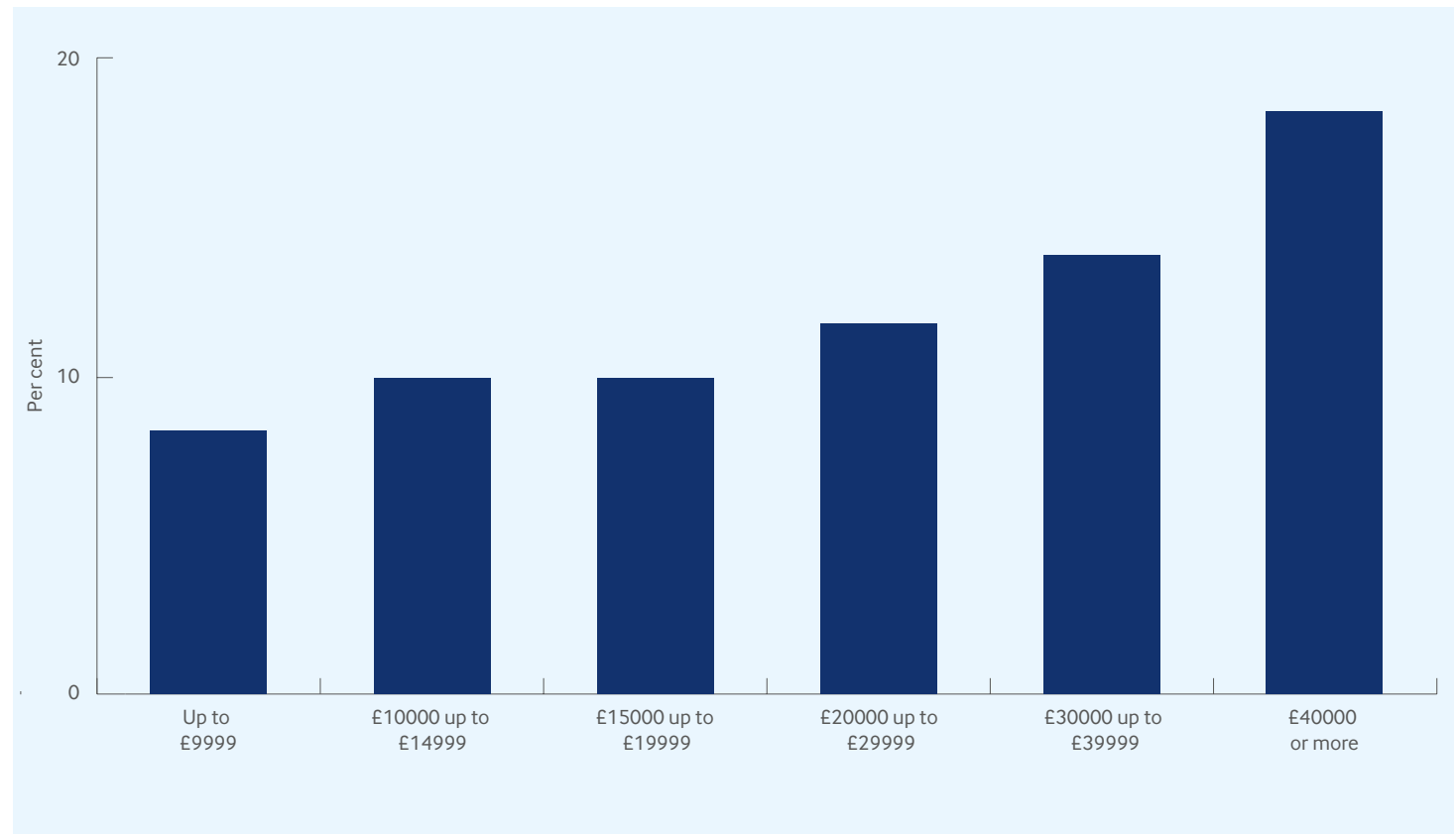

Source: Office for National Statistics Statistical Bulletin (2016)

Adult drinking habits in Great Britain, 2014 Newport: Office for National Statistics

The type of occupation also has an impact on drinking patterns and levels of consumption. Individuals in managerial and professional occupations, especially those working for large employers, are more likely to have drunk alcohol in the previous week and to drink more frequently than those in routine and manual occupations (see Table 2).

Table 2: comparison of drinking patterns between individuals aged 16 to 64 in different occupations, 2011, Great Britain

\begin{tabular}{|c|c|c|}
\hline & Managerial and professional & Routine and manual \\
\hline $\begin{array}{l}\text { Drunk alcohol in last week } \\
\text { Women } \\
\text { Men }\end{array}$ & $\begin{array}{l}64 \% \\
75 \%\end{array}$ & $\begin{array}{l}43 \% \\
59 \%\end{array}$ \\
\hline $\begin{array}{l}\text { Consumed an alcoholic drink } \\
\text { on five or more days in the } \\
\text { previous week }\end{array}$ & $16 \%$ & $9 \%$ \\
\hline
\end{tabular}

Source: Office for National Statistics (2013) General Lifestyle Survey overview - a report on the 2011 General Lifestyle Survey Newport: Office for National Statistics. 
Surveys of employers and business across the UK have found that many employees are affected by alcohol consumption during working hours. A survey performed in December 2007 for Norwich Union Healthcare found a third of employees admitting to attending work with a hangover. ${ }^{19} 15$ per cent reported having been drunk at work. One in 10 employees reported hangovers at work once a month, and one in 20 once a week. Work problems resulting from hangovers or being drunk at work included difficulty concentrating, reduced productivity, tiredness, and mistakes. The majority (77\%) of employers interviewed for this survey identified alcohol as a major threat to employee wellbeing and a factor encouraging sickness absence. A 2006 PruHealth survey found that over 200,000 people go to work in Britain with a hangover on any given day, and that one-in-five 18-25 year olds go to work with a hangover once a fortnight or more. ${ }^{20} \mathrm{~A}$ survey undertaken in 2004 by reed.co.uk suggested that workers turn up at work with a hangover on an average of two and a half days per year. ${ }^{21}$

\section{Illicit drugs}

Various surveys provide an indication of the level of illicit drug use among people in employment. A questionnaire survey published by the Health and Safety Executive (HSE) in 2004 reported that:

- 13 per cent of working respondents of all ages reported drug use in the previous year, the rate varying with age

- 29 per cent of workers under the age of 30 years reported drug use in the previous year

- Working drug users were more often smokers, heavy drinkers, male, under 25, single, well educated, resident in a more affluent urban area, and scored highly on a neuroticism scale. ${ }^{13}$

The HSE research was based on data from a postal community survey in Cardiff and Merthyr Tydfil, and a survey of people attending accident and emergency (A\&E) departments in Wales. A total of 4,620 people in employment completed the community survey, and 1,994 people in employment completed the A\&E survey. Among the 4,620 workers who completed the community survey, 38 per cent reported ever having used drugs, 13 per cent reported using drugs in the last year, and seven per cent in the last month. ${ }^{13}$ Cannabis was the most commonly reported drug used in the last year (11\%), followed by ecstasy (2.5\%), amphetamines (2.3\%), and cocaine (2.2\%). ${ }^{11}$ Among the 1,994 workers who completed the A\&E survey, 51 per cent reported ever having used drugs, 21 per cent reported using drugs in the last year, and 12 per cent in the last month. ${ }^{11}$ Cannabis was the most commonly reported drug used in the last year (19\%), followed by amphetamines (6\%), ecstasy (5\%), and cocaine (4\%). ${ }^{11}$

Previous work suggested that the rates of use among workers may be lower than those of the unemployed, however, the gap between the two groups narrowed in the late 1990s. ${ }^{22}$ Reported use of any illicit drug is highest for those living in areas defined to be the most deprived (10.2\%), and lowest for those living in areas defined to be the least deprived (6.9\%). However, use of any Class A drug does not vary with Indices of Deprivation. ${ }^{12}$

As is the case for alcohol use, for individuals in employment, there is some evidence that illicit drug use is affected by the type of occupation. According to the Scottish Crime and Justice Survey for 2010-11, those working in routine and manual occupations were twice as likely to report using illicit drugs in the last year than those in managerial and professional occupations, and those who were not working or who were long-term unemployed. ${ }^{17}$ The newspapers portray an entirely different picture with 40 per cent of news stories of drug use being among professionals and celebrities, with (offenders excluded) only around six per cent of stories relating to non-professional workers and the unemployed. ${ }^{23}$

\subsection{International perspective}

According to the US Census Bureau, small businesses with fewer than 500 employees are particularly disadvantaged by worker substance use, and about half of all US workers are employed by small and medium sized businesses. Approximately 90 per cent of the US workforce who are heavy drinkers, current illicit drug users or who have alcohol or illicit drug dependence, work for small and medium size firms. ${ }^{24}$

\section{Alcohol}

USA national survey data from 2013 revealed that:

- full-time employed adults are more likely to drink (65.8\%) compared to the unemployed (53.8\%)

- the rate of binge drinking among employed and unemployed persons was similar

- most binge and heavy alcohol users were employed - 44.5 million adult binge drinkers were in employment ( $76.1 \%$ of all binge drinkers) and 12.4 million persons reporting heavy alcohol use were in employment ( $76 \%$ of all heavy drinkers). ${ }^{25}$ 
In New Zealand over three per cent of adults reported harmful effects on their work, study or employment in the last 12 months due to their own alcohol use. Around three per cent also reported having operated machinery while feeling under the influence of alcohol in the preceding 12 months, reaching 10 per cent among males aged 18-24 years. ${ }^{26}$ In Australia it is reported that about five per cent of the population attend work while under the influence of alcohol. ${ }^{27}$ High risk levels of consumption are more prevalent among particular occupational groups, including young workers, workers in blue-collar occupations, and workers employed in the hospitality, agriculture, manufacturing, construction, and retail industries. ${ }^{28,29}$

\section{Illicit drugs}

USA national survey data from 2013 revealed that the rate of current illicit drug use was higher for the unemployed (18.2\%) than for those employed full time (9.1\%), employed part time (13.7\%), and students, carers, retired or disabled persons, etc (6.6\%)

- substance dependence or abuse was more prevalent among unemployed adults aged 18 or older (16.9\%) than full-time employed adults (9.1\%) or part-time employed adults (10.3\%)

- Of the 22.4 million adults classified with dependence or abuse, 15.4 million (68.9\%) were employed full time or part-time 25

In New Zealand around three per cent of past-year cannabis users reported having had one or more days off work or school in the past year due to their cannabis use. Among past-year amphetamine users one in four reported having worked while feeling under the influence of amphetamines in the past year whilst one in nine reported having operated machinery. ${ }^{26}$

\subsection{Summary}

- Although there is insufficient data to know precisely the extent of the problem, it is evident that alcohol and illicit drug use is prevalent in those who are in work and as such is a significant issue for the workplace and a growing concern for employers

- Individuals in employment are more likely to drink frequently compared to those who are unemployed.

- Individuals in managerial and professional occupations are likely to drink more frequently than those in routine and manual occupations

- Data suggests that the rates of illicit drug use among workers may be lower than those of the unemployed, however, the gap between the two groups appears to be narrowing and it is clear that a significant proportion of working respondents use illicit drugs 


\section{Chapter 3 - The burden of the problem}

Alcohol and illicit drug use is associated with a range of physical, psychological and social harms, which inflict an economic burden on employers, governments and society. There is little quality evidence of the impact of the harm associated with alcohol and illicit drug use in the workplace, and the financial and other costs are difficult to measure. ${ }^{30}$ Many costs are hidden by general absenteeism or illnesses, unnoticed lack of productivity, or inability or reluctance to link substance use directly with causes of accidents. Table 3 provides an overview of the effects of alcohol and illicit drug use and associated costs to employers.

Table 3: overview of the effects of alcohol and illicit drug use and associated costs to employers

\begin{tabular}{|c|c|}
\hline Effects of alcohol and drug use & Associated employer costs \\
\hline $\begin{array}{l}\text { Absenteeism (days off; lateness; long lunch break; } \\
\text { sleeping on the job; unauthorised leave) }\end{array}$ & $\begin{array}{l}\text { Lost time } \\
\text { Lost productivity } \\
\text { Lower profits }\end{array}$ \\
\hline $\begin{array}{l}\text { Presenteeism (Impaired workplace performance } \\
\text { deterioration in quantity and quality of work; } \\
\text { impaired judgment and decision-making; } \\
\text { reduced reaction times and efficiency; increased } \\
\text { error rates) }\end{array}$ & $\begin{array}{l}\text { Lower productivity, reduced product and } \\
\text { service quality, } \\
\text { Lower profits } \\
\text { Potentially reduced company reputation, corporate } \\
\text { image; and competitive strength }\end{array}$ \\
\hline Health issues & $\begin{array}{l}\text { Sick pay } \\
\text { Private medical plans (where employer-provided) }\end{array}$ \\
\hline Workplace injuries and incidents & $\begin{array}{l}\text { Legal fees/fines } \\
\text { Increased insurance costs }\end{array}$ \\
\hline $\begin{array}{l}\text { Inappropriate behaviour eg, leading to } \\
\text { disciplinary procedures }\end{array}$ & Management time \\
\hline Job losses, staff turnover and recruitment costs & $\begin{array}{l}\text { Management time } \\
\text { Recruitment and training of replacements } \\
\text { Loss of company knowledge }\end{array}$ \\
\hline Theft to support a drug habit & $\begin{array}{l}\text { Replacement of property } \\
\text { Security staff and crime prevention }\end{array}$ \\
\hline $\begin{array}{l}\text { Co-worker relations and morale (increased } \\
\text { workload or stress levels for other workers) }\end{array}$ & $\begin{array}{l}\text { Negative impact on performance, productivity } \\
\text { and quality }\end{array}$ \\
\hline
\end{tabular}

Adapted from: Accident Compensation Corporation,

Wellington: Accident Compensation Corporation.

\subsection{Physical, psychological and social burden to workers}

\section{Alcohol}

Alcohol is a central nervous system (CNS) depressant; it impairs balance, co-ordination, perception, reaction time and reasoning. These effects compromise the ability to drive and operate machinery, which can lead to accidents and injuries. Many skills and cognitive processes begin to decline at levels lower than the prescribed blood alcohol concentrations (BAC) permitted for driving. ${ }^{31}$ Drivers who have a BAC of $30-60 \mathrm{mg} / \mathrm{dl}$ have impaired ability to negotiate a test course with artificial hazards; a BAC of 50mg/dl may disturb memory transfer from immediate recall to permanent storage; and impaired performance can be demonstrated at a BAC as low as $11 \mathrm{mg} / \mathrm{dl}$ in pilots in flight simulators. ${ }^{31}$ 
Alcohol is causally related to over 60 different medical conditions. Conditions that show increasing risk of harm from even low levels of consumption include cancers of the lip, oral cavity, pharynx, oesophagus and breast; and at higher levels, increasing risk of cancers such as liver and colorectal cancer. Alcohol also contributes to the risk of epilepsy, hypertension, arrhythmias, cardiomyopathy, stroke, cirrhosis, pancreatitis, polyneuropathy. . $^{32,33,34}$

It is clear that acute and chronic effects of alcohol consumption can have a direct impact on a worker's health and wellbeing, as well as an indirect impact through inability to work through ill-health.

\section{Illicit drugs}

There are well documented links between illicit drug use and impairments in cognition, perception, and motor skills. ${ }^{13}$ Much of the evidence is based on laboratory based studies showing that motor coordination, perceptual abilities, and cognitive function are lowered among drug users, or after particular drugs have been taken.

Cannabis can have an adverse effect on any complex learnt psychomotor task and can cause temporal disorganisation with disruption of correct sequencing of events in time; a single 'joint' can cause measurable impairment of cognitive skills for more than 10 hours due to its half-life of 36 hours. ${ }^{31}$ The knowledge base on how this impairment affects safety in the workplace remains relatively small. ${ }^{31}$ Research conducted for the HSE - using a community based questionnaire survey and a cohort study of workers carrying out cognitive performance tasks - showed a significant negative impact of illicit drug use on work performance. ${ }^{13}$ Illicit drug users had slower reaction times during concentration and attention tasks, performed less well at reasoning and memory tasks, and had lower alertness and hedonic tone scores. ${ }^{13}$ Users were just over half as likely again as non-users to report quite frequent or very cognitive failures, and more likely than non-users to report minor injuries at work (but only among those with higher levels of other associated risk factors). The study found no evidence for an association between illicit drug use and workplace accidents. Overall, the study data provided little evidence for any significant impact of illicit drug use on work-related road traffic accidents, except perhaps among those reporting only cannabis use in the last year together with high levels of other risk factors. The very small numbers of workers reporting such accidents mean that these findings must be interpreted with caution. ${ }^{13}$

Although a possible impact on work seems intuitively obvious, few studies have specifically examined this relationship, and the evidence relating to accidents at work is somewhat contradictory.

As with alcohol use, illicit drug use is associated with various acute and chronic primary and secondary harms that can directly and indirectly affect an individual's health and wellbeing. ${ }^{35}$

\subsection{Burden to employers}

\section{Alcohol}

Use of alcohol or illicit drugs can impair a person's performance at work through poor decision making and impaired reaction times causing lost productivity, inferior goods/services, errors and accidents. There are no precise figures on the number of workplace accidents where alcohol is a factor.7 90 per cent of personnel directors from top UK organisations surveyed in 1994 stated that alcohol consumption was a problem for their organisation. Most considered alcohol to affect only a small number of employees, however, 17 per cent of personnel directors described alcohol consumption as a 'major problem' for their organisation. A UK study published in 1981 estimated that alcohol caused three to five per cent of all absence from work, equating to about eight to 14 million working days in the UK each year. ${ }^{36}$ Alcohol consumption has increased since the early 1980s, and a study undertaken in 2001 across the UK workforce calculated that over 176 million working days were lost due to sickness and absenteeism, with six to 15 per cent (ie about 11-17 million days) attributed to alcohol related sickness. ${ }^{37}$ In 2010 , the National Institute for Health and Clinical Excellence estimated that the cost of alcohol-related employee absenteeism in England was $€ 1.7 \mathrm{bn} .^{38}$

\section{Illicit drugs}

While it is reasonable to consider that illicit drug use may lead to increased sickness absence and performance problems, the evidence on the links between drug use and accidents at work, absenteeism, low productivity and poor performance is inconclusive. ${ }^{39}$ Apart from a few exceptions, there is a lack of evidence for a strong link between illicit drug use and accidents in safety critical industries, such as transport, engineering, quarrying and mining. Evidence suggests that alcohol is probably a greater cause for concern in the workplace than illicit drugs. ${ }^{39}$ 


\subsection{Burden to society}

Various data show that the cost of alcohol and illicit drug use on society is substantial. These range from estimates of the total economic and social costs, to data on the impact on the benefits system.

\section{Alcohol}

The costs of alcohol misuse in England are estimated to be about $€ 21$ billion per year. ${ }^{40}$ This estimate includes: NHS costs of around $€ 3.5$ billion per year; alcohol-related crime, at $€ 11$ billion per year; ${ }^{40}$ and lost productivity at about $€ 7.3$ billion ${ }^{41}$.

The estimated cost to the productive capacity of the Scottish economy in 2007 - related to foregone productive capacity by workers due to absenteeism, presenteeism, unemployment and premature alcohol-related mortality - was between $€ 725.2-€ 1,006.1$ million (mid-point $€ 865.7 m i l l i o n)$. The cost of absenteeism was estimated to be between $€ 109.4$ million- $€ 273.5$ million and the cost of presenteeism was estimated to be between $€ 177.0$ million- $€ 193.1$ million. The larger cost is not that attributable to absenteeism (ie measurable lost days of work), but from presenteeism (ie impaired productivity while on the job). ${ }^{21}$

A study looking at the costs of alcohol-related harm across Scotland in 2009-10 estimated that the labour and productivity costs (which covered presenteeism and absenteeism, unemployment and premature mortality) were between $€ 866$ million- $€ 1,062$ million (mid-point $€ 964$ million). ${ }^{42}$ The 2004 reed.co.uk survey noted previously found that workers turning up to work with a hangover thought that they were 27 per cent less efficient on these days. This led the Info.Scotland.com website to suggest that the productivity lost to hangovers could therefore account for an additional 1.62 million lost days, at a cost of €154 million. ${ }^{21}$

Approximately 400,000 benefit claimants (around $8 \%$ of all working age benefit claimants) in England are dependent on drugs or alcohol, with benefit costs of approximately $€ 1.6$ billion per year. ${ }^{43,44}$ Approximately 160,000 individuals in receipt of one or more 'main benefits' are estimated to be experiencing physical and social problems (including, possibly, problems maintaining employment) due to their excessive alcohol consumption. Approximately 100,000 of this group are in receipt of incapacity benefit, 90,000 in receipt of income support, just under 30,000 in receipt of disability living allowance, and 25,000 in receipt of jobseekers allowance. ${ }^{44}$

\section{Illicit drugs}

There is very limited information on the workplace economic cost of illicit drug use in the UK. According to Scottish Government Social Research, the total cost of absenteeism, lost productivity and lost output associated with illicit drug use in Scotland was estimated at $£ 818.9$ million. ${ }^{45}$

\subsection{International Perspective}

In the USA, the financial loss attributed to alcohol and drugs in the workplace has been found to occur mainly for the following reasons:

- workers compensation - 38 to 50 per cent of all claims are related to substance use, with users filing three to five times as many claims

- medical costs - substance users incur 300 per cent higher medical costs than non-users

- absenteeism - substance users are 2.5 times more likely to be absent eight or more days a year

- lost productivity - substance users are a third less productive

- employee turnover - it costs a business an average of $\$ 7,000$ to replace a salaried worker. ${ }^{46}$

\section{Alcohol}

Lost productivity costs feature as the dominant element in social costs studies arising from the harm caused by alcohol use. Alcohol is a significant risk factor for absenteeism and presenteeism at work, largely in a dose response manner, with a relationship between societal and individual level of alcohol consumption and sickness absence. ${ }^{47} \mathrm{~A}$ Finnish study reported that the direct relationship between alcohol consumption and sickness absence is particularly pronounced for low-educated males. ${ }^{48}$ Studies suggest that alcohol consumption may have more effect on productivity on the job than on the number of workdays missed. ${ }^{49}$ Estimates for the costs of lost productivity attributable to alcohol include: Canada $\$ 7.1$ billion in 2002, ${ }^{50}$ Australia A $\$ 3.6$ billion in 2004-05, ${ }^{51}$ India 70,000-80,000 million rupees in 1997,52 and the USA $\$ 134.2$ billion in 1998 (the last year for which costs were estimated). ${ }^{53}$ 
In Australia, high-risk drinkers are up to 22 times more likely to be absent from work due to their alcohol use compared to low-risk drinkers. ${ }^{54}$ Short-term high-risk drinkers were also significantly more likely to be absent from work due to any illness or injury than employed low-risk drinkers. ${ }^{44}$ Young employees and males were more likely to report alcohol-related absenteeism compared to older workers and females. ${ }^{54}$ Data from the 2004 National Drug Strategy Household Survey revealed that: 4.4 per cent of Australians went to work affected by alcohol; the workplace was the usual place of consumption of alcohol for over six per cent of participants. ${ }^{30}$ Alcohol has been found to be a contributing factor in an estimated four per cent of work-related fatalities. ${ }^{55}$

Studies from Australia, Canada and USA estimate the fraction of occupational and machinery injuries attributable to alcohol to range between seven and 25 per cent. ${ }^{56}$ In India, 15 to 20 per cent of absenteeism, and 40 per cent of accidents at work, are due to alcohol consumption. ${ }^{56}$ In Costa Rica, it has been estimated that 30 per cent of absenteeism and workplace accidents were caused by alcohol dependence. ${ }^{56}$ In Chile, 20 to 22 per cent of work-related accidents have a direct or indirect relationship with recent alcohol use, and in France alcohol is the cause of 10 to 20 per cent of work accidents. ${ }^{56}$ Two Scandinavian studies reported that a one litre increase in total alcohol consumption was associated with a 13 per cent increase in sickness absence among men, but not among women. . $^{57,58}$

\section{Illicit drugs}

Estimates for the costs of lost productivity attributable to drug use include: Canada $\$ 4.7$ billion in $2002^{50}$ and Australia A $\$ 1.6$ billion in 2004-05..$^{51}$ In Australia it is estimated that two per cent of people attended work affected by illicit drugs, ${ }^{30}$ and that drugs contribute to two per cent of workrelated fatalities. ${ }^{55}$

\subsection{Summary}

- Alcohol and illicit drug use impacts on cognitive performance which leads to cognitive failures affecting performance efficiency and safety at work. There are also hidden costs in general absenteeism or illnesses, errors, unnoticed lack of productivity and accidents

- The limited data and lack of accurate or standardised methodologies for measuring presenteeism and accidents linked to alcohol or illicit drug use makes it difficult to accurately estimate these costs. However, the burden is substantial to workers, business, society and to economies as a whole 


\title{
Chapter 4 - Occupational influences
}

Certain working situations and conditions are associated with alcohol and drug problems (ie shift or night work, travel away from home, working remotely, business meals, poor communications and job stress, etc). ${ }^{59}$ Factors within the workplace culture that present an increased risk for the use of substances include availability, work pressures, peer group pressure, co-worker collusion, lack of supervision, physical danger, and interface with a demanding or aggressive public. Many wider factors have also been documented such as domestic pressures, financial independence and financial hardship. ${ }^{60}$

\subsection{Occupations at risk for alcohol use}

Using mortality data among men and women aged 16-74 years in England and Wales during 1991- 2000, the highest mortality from alcohol-related diseases and injuries was observed in publicans and bar staff (both sexes), and in male caterers, cooks and kitchen porters, and seafarers. ${ }^{61}$ Data for $2001-05$ showed that for both sexes, those working in the drinks industry, including publicans and bar staff, were at high risk, while low indicators of alcohol-related deaths were found for men who worked as farmers and drivers, and women who worked with children. ${ }^{62}$ Male doctors were among the occupations with the highest indicators of alcohol-related deaths through the 1960s to the 1980s. In 2001-05, male doctors had a premature mortality rate of only 58 , suggesting that there was a significant change in alcoholrelated mortality among this group. This may be similar to the situation with smoking where, once the hazards were recognised, doctors gave up smoking earlier than the general population. Trends in alcohol consumption within the medical profession are not readily available, although figures from the GHS for 1988 and 1990 indicated that the proportion of male doctors drinking at levels which exceeded weekly recommended units of alcohol was lower than the population as a whole. ${ }^{62}$

A stressful psychosocial work environment is a risk factor for alcohol dependence. Analysis of the Whitehall II cohort of London-based civil servants study found a clear grade gradient for women, with those in the highest two grades having the highest proportion of problem drinkers, which was not the case for men. ${ }^{63}$ Effort-reward imbalance at work is associated with alcohol dependence in men, while low decision latitude is associated with alcohol dependence in women, particularly in higher occupational grades. ${ }^{63}$

\subsection{Occupations at risk for illicit drug use}

Using mortality data among men and women aged 16-74 years in England and Wales during 1991- 2000, the highest mortality from illicit drug dependence and accidental poisoning by illicit drugs was among the literary and artistic occupations and construction industry trades (male painters and decorators, bricklayers and masons, plasterers, and roofers and glaziers). ${ }^{61}$

\subsection{International perspective}

\begin{abstract}
Alcohol
In the USA between 2002-04, the major occupational groups with the highest prevalence of past month heavy alcohol use were construction and extraction occupations (17.8\%), and installation, maintenance, and repair occupations (14.7\%). Community and social services occupations (2.8\%) had the lowest prevalence of past month heavy alcohol use of the major occupations. The prevalence of alcohol dependence or abuse is highest among construction and extraction occupations (16.9\%), and food preparation and serving related occupations (14.7\%). ${ }^{64}$
\end{abstract}

Swedish census-linked deaths registry data (from 1980 and 1990 censuses) show that for both sexes, manual workers, lower non-manuals and entrepreneurs had significantly higher alcohol-related mortality than did upper non-manual workers, whereas male farmers had significantly lower such mortality. ${ }^{65}$ Women in male-dominated high-risk occupations also often showed increased relative risks. Stable and newly recruited employees in the same occupation showed very similar relative risks. ${ }^{66}$

A systematic review and meta-analysis of 61 studies from 14 countries reported that the maximum adjusted odds ratio for the association between long working hours and alcohol use was 1.11 (95\% confidence interval 1.05 to 1.18 ). The odds ration was similar for new onset risky alcohol use. There was no difference in these associations between men and women or by age or socioeconomic groups, geographical regions, sample type, prevalence of risky alcohol use in the cohort, or sample attrition rate. The authors concluded that individuals whose working hours exceed standard recommendations are more likely to increase their alcohol use to levels that pose a health risk. ${ }^{67}$ 


\section{Drugs}

In the USA between 2002 and 2004, the highest rates of past month illicit drug use were found among food service workers (17.4\%), construction workers (15.1\%), and those working in the arts, entertainment and media (12.1\%). The major occupational groups with the highest prevalence of illicit drug dependence or abuse in the past year were food preparation and serving related occupations (6.5\%), and construction and extraction occupations $(6.2 \%){ }^{64}$

\subsection{Summary}

- Certain working situations and conditions are associated with alcohol and drug problems (ie shift or night work, travel away from home, working remotely, business meals, poor communications and job stress, etc). International evidence also suggests that longer working hours are significantly associated with higher rates of alcohol use and related problems

- Factors within the workplace culture that present an increased risk for the use of substances include availability, work pressures, peer group pressure, co-worker collusion, lack of supervision, financial hardship, financial independence, physical danger, and interface with a demanding or aggressive public

- Those working in the drinks industry (both sexes) are at high risk of alcohol-related deaths, while those working as farmers and drivers, and women who worked with children, are lower risk. Male doctors were among the occupations with the highest indicators of alcohol-related deaths through the 1960s to the 1980s but appear to be less at risk nowadays

- The highest mortality from illicit drug dependence and accidental poisoning by illicit drugs was among the literary and artistic occupations and construction industry trades 


\section{Chapter 5 - Driving for work}

Driving vehicles is an activity inherently associated with employment. Individuals may drive vocationally, or may be employed for their professional driving skills - such as taxi drivers, driving instructors, chauffeurs, bus drivers, lorry drivers, delivery drivers. Driving may be intrinsic to working activities, such as sales representatives, warehouse and fork lift truck work, driving emergency services vehicles, working in construction and farming industries. Many individuals will choose to drive when travelling between business locations and, indirectly, many will drive as part of their daily commute.

\subsection{Driving and accidents}

Driving is also one of the biggest risks that many workers will face in their occupation. It has been estimated that up to one third of all road traffic accidents involve somebody who is at work at the time. ${ }^{68}$ Driving in work has been associated with 25-35 per cent of all fatal accidents on public roads, and is far in excess of any other fatal accidents in the workplace. ${ }^{69}$ Driving 25,000 miles per year occupationally carries an annual mortality risk of 1: 8,000 - higher than that of working in the construction, or mining and quarrying industries, and similar to that of working in the deep sea fishing industry. ${ }^{68,70,71}$ Despite this, the general perception of driving is often that of a relatively benign, low risk activity, ${ }^{72}$ when in reality the cumulative risk of injury over a lifetime of transport is comparatively high.73

The dangers of mixing driving with illicit drugs and/or alcohol are well known. Alcohol and illicit drugs are significant contributory factors in road traffic crashes, directly and potentiating other factors such as fatigue, low arousal, and effects of medication, leading to increased risk taking and impairment to coordination, visual perception, tracking and vigilance. Alcohol and illicit drugs in combination potentiate the effects of each other. Alcohol or illicit drugs contribute to 14 per cent and three per cent of fatal road accidents respectively. In Britain for 2014/15 the proportion of drivers who self-reported driving whilst either over the legal alcohol limit or under the influence of illegal drugs was around six per cent and one per cent respectively. ${ }^{74}$

\subsection{Medical standards for driving licences}

The principal legislation governing driving in the UK are the Road Traffic Act 1988 the Motor Vehicles (Driving Licence) Regulations 1999 and the Drug Driving (Specified Limits) (England \& Wales) Regulations 2014 (and subsequent amendment, 2015). To drive on public highways requires a licence. For most driving a class one licence suffices, and requires a self-declaration of health and a vision test. Driving vehicles greater than 3.5 tonnes or carrying more than eight passengers (large goods vehicles and passenger carrying vehicles respectively) requires a class two licence, with more stringent medical requirements and regular, age dependent health assessments. The body responsible for granting licences, and for setting medical standards for each, is the Driver and Vehicle Licensing Authority (DVLA) (Driver and Vehicle Agency (DVA) in Northern Ireland). These standards, and the impact upon each license of specific medical conditions, are set out in the DVLA document "Assessing fitness to drive - a guide for medical professionals" ${ }^{75}$ This guide is reviewed and updated regularly, and is thus best accessed via the internet.

The law requires:

- drivers must not drive while impaired by alcohol or drugs

- and in any case, drivers must not drive with blood, breath or urine alcohol levels or blood drug levels in excess of statutory limits (unless the drug is a prescribed medication, the doctor has discussed fitness to drive, and the individual's driving is unimpaired by the medication).

\subsection{Driving, declaration and disclosure}

The law also places a statutory duty upon drivers to inform the DVLA if they have, or develop, a "prescribed" or "relevant" disability, or if they have been diagnosed with a condition likely to progress to becoming a prescribed or relevant disability - a "prospective" disability. Specified within the list of conditions is "persistent alcohol misuse or dependency" and "persistent drug use or dependency". What is not often appreciated is that both conditions are considered prospective as well as prescribed. 'Assessing fitness to drive - a guide for medical professionals' gives further definition on notifiable conditions. ${ }^{76}$ 
Recognising that few individuals with drug or alcohol problems will self-declare to the DVLA, the GMC has advised doctors:

- to advise patients with a relevant or prospective disability of their obligation to inform the DVLA

- if the condition renders the patient unfit or unsafe to drive, to advise him or her to cease driving

If the patient continues to drive when they may not be fit to do so, and if attempts to persuade the patient to stop are unsuccessful, the doctor must disclose relevant medical information directly to the DVLA in the public interest. These requirements are set out by the GMC in the document Good Medical Practice: Confidentiality. ${ }^{76}$ More detail on, and suggestions on how to approach this difficult ethical situation is available from the DVLA and in explanatory guidance from the GMC. ${ }^{77}$ Prior to disclosure of an individual case doctors may also consider it prudent to discuss the circumstances and specific issues with an experienced colleague, or in the NHS, with the Trust's Caldicott Guardian. This would provide a check on this being the correct action and would help the doctor to defend his/her actions should the patient make a complaint to the GMC or anyone else about the disclosure.

\subsection{International perspectives}

Regulatory requirements, for example the maximum permitted blood ethanol concentration for professional drivers, vary considerably between countries and this paper does not intend to review the many relevant regulations. In some countries for some occupations testing is mandated by law (eg the Federal Motor Carrier Safety Administration's Regulations in the USA require alcohol and drug testing of drivers, who are required to have a commercial driver's license). The US Department of Transportation rules include procedures for urine drug testing and breath alcohol testing.

Increases similar to those mentioned above in the incidence of illicit drug detection in fatal accidents for a similar period have been recorded internationally, and the prevalence of drivers under the influence of illicit drugs in the European Union has increased significantly since the late 1990 's. ${ }^{78}$ A systematic review of psychoactive substance use in truck drivers noted that most studies were performed in countries with large land areas eg Brazil, the USA and Australia. ${ }^{79}$ The prevalence of the use of substances varied greatly possibly influenced by the methodologies used to obtain data and the different populations studied: alcohol (0.1-91.0\%); amphetamines (0.2-82.5\%), cannabis (0.2-29.9\%), cocaine (0.1-8.3\%). The use of these substances was associated with indicators of poor working conditions eg longer trips, driving in the night shift, fewer hours of rest. ${ }^{79}$

\subsection{Summary}

- Given the numbers of people in employment with illicit drug or alcohol problems described earlier in this report, as well as the strong association between driving and employment, it is inevitable that the two will overlap

- Alcohol and illicit drug use are significant contributory factors in serious and fatal road traffic crashes.

- Workers with illicit drug or alcohol problems who drive (or their doctors) have a duty to declare these to the DVLA 


\section{Chapter 6 - Workplace policies}

The burden that the alcohol and illicit drug use places on organisations makes it, at the very least, advisable for employers to have a substance use policy. This should form part of an organisation's overall proactive commitment to health and safety in order to safeguard individual employees, co-workers, customers and the public. Alcohol and illicit drug use policies and programmes should promote the prevention, reduction and management of alcohol- and illicit drug-related problems in the workplace. ${ }^{80}$

Where a medical professional is asked for advice by an employer they must establish the capacity in which they are being asked for advice and make clear to patients their professional role. Medical professionals should seek to understand the employer's alcohol and illicit drug use policy, and the support that is available to employees. Medical professionals who are also employers (eg GPs) should ensure that their workplace policies address alcohol and illicit drug use.

\subsection{Principles}

A workplace alcohol and illicit drug use policy will normally define what is meant by use, and include statements on why the policy exists, to whom it applies, the rules regarding alcohol and illicit drugs, and the support available to employees who have a drug problem., The policy should incorporate a statement encouraging those with a problem to seek help voluntarily. The following are common principles that are generally addressed within workplace alcohol and illicit drug use policies:

- alcohol and illicit drug problems should be considered to be health problems

- alcohol and illicit drug problems will be dealt with confidentially (subject to the provisions of the law)

- the employee is expected to comply reasonably with the management of his or her condition

- employees should not attend work under the influence of alcohol or illicit drugs

- consideration is given to postponing any disciplinary action during medical management

- sickness absence will be authorised if indicated - absence relating to alcohol or illicit drug use will be treated no differently to absence from any other cause under absence policies

- information about attendance and compliance with treatment is provided by the healthcare provider to the employer. ${ }^{7,8,80}$

\subsection{Policy framework}

A policy statement should include the following elements:

- coverage: the programme should apply to all employees.

- timely intervention: to ensure early identification and treatment of problems

- participation: involvement in a treatment programme should be voluntary and should not prejudice an employee's job security or chances of promotion

- confidentiality: personal information on employees undergoing treatment should be kept confidential

- training, education and communication: committing to prevent alcohol- and illicit drug-related problems in the workplace through information, education and training.

- referrals: any referrals for medical assessment may be by self-referral or manager-referral

- reintegration: this should describe the duties and responsibilities of the worker during and after treatment

- discipline: the employee should not be disciplined or discharged as long as he/she participates in rehabilitation and is progressing towards an acceptable level of job performance. Failure to comply may result in disciplinary action up to and including dismissal

- legal duty: a statement that possession/dealing will be reported immediately to the police and that there is no alternative to this procedure..$^{8,80}$

Managers and supervisors should be trained to recognise the signs of problems with alcohol and illicit drug use. They should know what to do if they suspect any substance use problems, or if they are approached by an employee who declares a problem. ${ }^{8}$ If screening or testing for alcohol or illicit drugs is performed, this should be defined in the policy. It is also advisable to incorporate any such requirement for compliance with possible alcohol and illicit drug testing in employees' contracts of employment. ${ }^{81}$

The policy should also advise employees that it might not be safe to take some prescribed and over the counter medication in some work circumstances. They should be advised to ask their health professional or pharmacist if the medication is likely to affect their work performance, and to report to their manager any information relevant to their likely capacity to do the job safely. There may be a need to make reasonable adjustments to work arrangements if performance-related effects are anticipated among employees engaged in safety-critical work. ${ }^{81}$ 


\subsection{International perspective}

A 2007 Cochrane systematic review of interventions for preventing injuries in the construction industry concluded that there is limited evidence that a multifaceted safety campaign, and a multifaceted drug program, can reduce non-fatal injuries in the construction industry. ${ }^{82}$ Three studies evaluated the effect of regulations, a safety campaign, or a drug-free workplace program. Regulatory interventions did not show either an initial or sustained effect on fatal or non-fatal injuries. The safety campaign had an initial and sustained effect, reducing non-fatal injuries. The drug-free workplace programme had an initial and sustained effect, reducing non-fatal injuries compared to no intervention.

In Australia, alcohol policies (accompanied by supporting procedures) are considered an integral part of workplace 'risk management', suggesting that such policies substantiate employers' 'duty of care' obligations, prevent procedural uncertainty, demonstrate commitment to safety and education, and facilitate 'peer support' that potentially positively informs workplace behaviour and culture. It has been suggested that workplaces should develop policies on a collaborative and consultative basis and they should be clearly communicated to all staff once developed. ${ }^{83}$

\subsection{Summary}

- All employers should have a substance use policy

- Drug policies are more successful when conceived as a component of health and welfare policy rather than primarily a disciplinary matter

- Alcohol and illicit drug use policies and programmes should promote the prevention, reduction and management of alcohol- and illicit drug-related problems in the workplace 


\section{Chapter 7 - Workplace screening and testing}

Little is known about the extent of screening and testing for alcohol and/or illicit drug use in the workplace setting in the UK. A small survey conducted for an independent inquiry in 2003 found that only four per cent of companies tested, and nine per cent planned to introduce testing. ${ }^{38}$ Many employers stated they would consider testing, if they believed alcohol and illicit drug use affected productivity (78\%), health and safety (89\%), or if they believed use was prevalent within their workforce (72\%). Employers and trades unions accept that testing is of value in safety-critical occupations (eg railway workers). Some employers view drug testing as an important part of their obligation under health and safety legislation. In non-safety critical areas, the benefits of testing are less obvious. ${ }^{84}$ Most employers who conducted testing told the inquiry that levels of positive results were very low. ${ }^{38}$ There is no clear evidence that drug testing at work has a significant deterrent effect. ${ }^{38}$

\subsection{Practical and legal issues of screening and testing}

Screening employees for alcohol and/or illicit drug use in the workplace is a complex and contentious topic involving moral, ethical and legal issues. ${ }^{77}$ Screening is only likely to be acceptable if it is clearly designed to prevent risks to others. ${ }^{7}$ Testing for alcohol is less contentious, particularly in safety-sensitive jobs. Alcohol testing directly assesses breath/alcohol levels, and these levels have been associated with given risk of impairment. However, the evidence base remains scant. ${ }^{80}$ The illegal nature of illicit drug use, the potential for confusion with prescribed medication, the lack of easily demonstrable dose-effect relationships, and the persistence of some substances create practical difficulties for testing programmes. Those undergoing testing should be invited to declare their use of any prescription, pharmacy or over-thecounter medication. ${ }^{78}$ Testing for illicit drugs does not assess current intoxication and reveals information about use that may have no impact on safety, productivity or performance. Someone may test positive after taking an illicit drug days, weeks or months prior to the test. ${ }^{38}$ Testing aims to confirm an individual's ability to work safely is not impaired by alcohol or illicit drugs.

Testing should only be introduced after careful consideration and alongside a detailed policy that sets out the reasons for testing, the procedures to be followed, and any role for health professionals. ${ }^{85}$ Legal issues around testing arise from the Human Rights Act 1998 (HRA), and the Data Protection Act 1998 (DPA). ${ }^{38}$ The HRA incorporated the European Convention on Human Rights into UK law. Article eight of the convention provides the right to private life which could have implications for the legality of testing for illicit drugs at work. The Information Commissioner's Employment Practices Code Part IV states that 'the collection of information through drug and alcohol testing is unlikely to be justified unless it is for health and safety reasons', and that employers should 'confine the obtaining of information through random testing to those workers who are to work in safety-critical activities' ${ }^{86}$ Post-incident testing where there is a reasonable suspicion that illicit drug or alcohol use is a factor is more likely to be justified than random testing.

The Equality Act 2010 does not regard impairment or dependency on alcohol or an illicit drug as a defence against testing.

Because of the practical and legal issues involved employers must secure the agreement of the workforce and/or their representatives to the principle of screening and to incorporate this in employees' contracts of employment. ${ }^{7,8}$ Employers should advise prospective employees of any screening for alcohol and illicit drugs as part of the recruitment process and whether a positive test precludes employment. ${ }^{82}$

A robust and comprehensive policy must be introduced before testing starts, and there should be an amnesty of a few months to allow current users to become abstinent or seek help.

\subsection{Consent and confidentiality}

Written consent is needed for each test. This consent applies only to tests relating specifically to alcohol and illicit drugs, and to no other substances, condition or disease. Medical confidentiality should be assured. The occupational physician and others involved should be clear as to the purpose and consequences of the test and distinguish clearly between tests for alcohol and illicit drugs and tests undertaken for clinical purposes. ${ }^{78}$ Where testing is part of a post-offer health assessment the occupational physician owes no legal duty of care to the subject (other than to ensure that the process is appropriate and valid). Good medical practice demands good clinical judgement and an appropriate analysis of risk in determining fitness for particular employment. ${ }^{78}$ 
Test results are classified as sensitive personal data under the terms of the DPA. Medical professionals should inform employers whether an employee is considered fit or unfit for work without disclosing the actual test result. A positive test does not in itself imply impairment, but it is a marker for behaviour involving use of illicit drugs that may affect safety at work. It indicates that alcohol and illegal substances have been used and therefore that at some point in the user's recent past they may have caused impairment. The test cannot tell whether the user is a habitual user or a one-off user. For habitual users of high doses of substances, the length of time the metabolites are present in the urine can be significantly longer (as in the case of cannabis). ${ }^{78}$

\subsection{Practical aspects of screening and testing}

Testing should be used and presented as a supportive tool to help identify any employee who might cause harm to themselves or others. UK drug testing services are provided by a disparate group of companies and individuals. Many are very responsible, but some may be making what appear to be inflated claims about the extent and impact of alcohol and illicit drug problems in the workplace, and the effectiveness of their own products. ${ }^{38}$ All major providers of laboratory services for alcohol and drug testing are members of the UK Workplace Drug Testing Forum (www.wdtforum.org.uk). Laboratories should be accredited to ISO17025 for laboratory quality management, and also participate in the UK National Quality Assurance Scheme for quality assurance of alcohol and illicit drug testing results.

Testing can be performed at the following times:

- recruitment: as part of selection process

- random: of all or part of the workforce routinely

- for cause: after an accident or incident to determine causation

- due cause: when an employee is suspected of being unfit because of possible intoxication

- group monitoring: for a particular problem (eg employees reporting for work with alcohol in their bloodstream from the previous evening's drinking)

- individual monitoring: as part on employee's rehabilitation programme assuring freedom from alcohol or illicit drugs for the purposes of entering the workplace, and assessing progress following return to work after detoxification treatment., ${ }^{7,30,78}$

Workplace drug testing is performed predominantly using urine samples for which there is extensive scientific information. Oral fluid and hair is used increasingly in routine workplace testing schemes. Scientific data validating the use of oral fluid and hair, as alternative sampling techniques, appears satisfactory to justify their potential routine use. Published data and limited information of sweat testing highlight possible concerns about the specificity of sweat wipe testing for some drugs. Urine, oral fluid and sweat drug tests reflect recent exposure. Hair testing identifies past drug use over weeks and months and so is not applicable for 'due-cause testing', but is considered more applicable to recruitment and rehabilitation testing. ${ }^{87}$

There is limited published data from large-scale workplace studies that compares the efficacy of a workplace drug-testing programme based on oral fluid versus urine testing. Analysis suggests that they have comparable efficiency in detecting recent illicit drug use. Both detect recent illicit drug use. The 'time window of detection' for most drugs in oral fluid is shorter than that for urine. A shorter detection window coupled with a more immediate detection after illicit drug use in oral fluid measurements may indicate a closer relation with 'impairment', and therefore of particular relevance in 'due-cause' testing. ${ }^{84}$

Chain of custody $(\mathrm{CoC})$ for donated samples is one of the key elements in the defensibility of individual results and maintaining the credibility of schemes in general. This maintains a proven link between a donated sample and the results reported for that sample, and ensures that samples are stored appropriately. The $\mathrm{CoC}$ procedures for workplace testing are modelled on the handling of forensic samples; the same principles are applicable for any sampling media. ${ }^{84}$ Any laboratory accredited by the National Measurement Accreditation Service will have satisfied assessors that it provides a service that meets all criteria. ${ }^{7}$ Normally, the collected sample is split at the point of collection into sample A and sample $B$. If a positive result is reported for sample $A$, the test subject has the opportunity to challenge this report and arrange for independent testing of sample B. Each stage of the chain must be capable of audit, enabling tracking, and validation of the integrity of the sample. ${ }^{78}$ 


\subsection{International perspectives}

Workplace drug testing is common in the USA. ${ }^{90}$ Nearly half of all workers have reported that their employer performs testing, with possibly 90 per cent of Fortune 200 firms undertaking them. ${ }^{91} \mathrm{Few}$ studies provide evidence that testing deters use; however illicit drug use (particularly cannabis) is lower in tested workforces. In studies with large negative correlations between testing and use, suggesting a deterrent effect, the conclusions may have been overstated due to omitted variables. Large negative associations are also found for where an employer has drug education, employee assistance programmes, and/or a written substance use policy. These workplace characteristics reduce, but do not eliminate, the testing differential. The overall pattern of results is largely consistent with drug testing deterring use.

A Cochrane systematic review of two USA studies assessed the effect of mandatory alcohol and drug screening of occupational drivers to prevent injury or work-related effects, such as sickness absence related to injury. ${ }^{92}$ In one study mandatory random and for-cause alcohol testing was associated with a significant decrease in the level of injuries immediately following the intervention, but did not significantly affect the existing long-term downward trend. There was insufficient evidence to advise for or against drug and alcohol testing of occupational drivers for preventing injuries as a sole, effective, long-term solution.

In Australia, some employers have adopted an approach that incorporates the opportunity to self test along with random testing and for-cause testing. If they test themselves using a hand-held breath-testing machine and record a positive result, they report sick. Usual procedures for sick leave are employed (eg frequent regular sick leave will be investigated and/or require a medical certificate). Although the approach seems to have some merit, no analysis has been reported. ${ }^{80}$

\subsection{Summary}

- Employers may use alcohol and drug testing at the recruitment stage and/or for testing of current employees

- Alcohol and drug testing has grown as a result of practice transferred from the USA and elsewhere, and it may become more commonplace in the UK. Its effect in reducing occupational injuries remains unclear, despite some robust reviews of the evidence

- A 2004 UK independent review identified some uncertainties in legal aspects with workplace drug testing (employment, health and safety, data protection, human rights and discrimination legislation), and in regard to workplace drug testing in general, the report indicates that testing related to safetycritical activities is defensible

- A robust alcohol and illicit drug use policy needs to be in place to avoid any potential pitfalls, and to comply with exiting legislation and guidance

- Good communication of policy by employers to employees, and potential employees, is essential; including guidance on drug and alcohol testing regarding what, to whom and for what purpose, and the consequences of refusal, are the essential elements of informed consent for that testing

- Samples for testing must be appropriately safeguarded, where appropriate, and tested by appropriate facilities

- Interpretation of results must be undertaken by practitioners who have the competence for the task (often referred to as Medical Review Officers)

- Results, and advice, should comply with medical best practice and data protection requirements 


\section{Chapter 8 - Management in the workplace}

Additional to the medical management of individuals with problems with alcohol and illicit drug use which is addressed in other guidance published by BMA Board of Science - it is important that health professionals are aware that: ${ }^{34,35}$

- a significant proportion of adults who are at risk for alcohol and illicit drug problems are employed, hence the workplace provides good opportunities for public health interventions

- most individuals who have problems with alcohol use, and many with illicit drug use problems, are in employment. Health practitioners need to consider their patient's job, including whether that patient is fit to attend work, to function safely in their job, and to perform specific duties, particularly where the safety of that individual, of co-workers and the general public might be at risk

\subsection{Workplace intervention programmes}

\section{Health promotion programmes}

There is limited evidence for workplace intervention programmes directed either toward at risk workers or an entire workforce. Workplace health promotion programmes aim to improve employee health and wellness through education aimed at behavioural change rather than addressing alcohol and drugs specifically. A systematic review of the association between work health promotion and job wellbeing, work ability, and absenteeism reported moderate evidence that work health promotion decreases sickness absences and increases mental but not physical wellbeing. ${ }^{93}$ Sickness absences appeared to be reduced by activities promoting healthy lifestyle but not by education and psychological methods. Another systematic review reported that two out of three studies on alcohol use found that health promotion programmes were associated with significant reductions in consumption. ${ }^{94}$ The studies yielded mixed results regarding the overall impact of wellness programmes on health-related behaviours and substance use, while the evidence for effects on absenteeism and mental health was insufficient. ${ }^{94}$

\section{Brief interventions}

Brief interventions typically involve personal assessment of an individual's lifestyle risks and related problems, as well as feedback about risks. Evidence is emerging from quality studies that brief interventions - including those delivered by web-based media - are accessible, acceptable and impact on a broad range of employees. This includes employees who are drinking at risky levels, as well as those who are easily identifiable as being dependent on alcohol, and who might appropriately be referred to more intensive counselling services. ${ }^{83} \mathrm{~A}$ recent study of screening and brief intervention for risky alcohol consumption at a large transport company found no significant differences between brief and comprehensive intervention groups, or between intervention groups and the control group, at followup 12 months later. ${ }^{95}$ The results suggested that alcohol screening and brief intervention performed in connection with routine health and lifestyle examinations in the workplace may be effective in reducing alcohol consumption. The lack of difference in outcome between intervention groups and the control group may indicate that alcohol screening (by questionnaire or bio-markers) may in itself cause reduction in drinking. Guidance published by NICE has stated that brief interventions can be used opportunistically in a variety of settings for people not in contact with drug services. ${ }^{96}$

\section{Web-based health interventions}

Recent research points to the potential effectiveness of web-based technology for improving health outcomes in the workplace. This is consistent with research in other settings (eg university students or as part of a general health intervention) that web-based brief interventions are acceptable, have good penetration into target groups, and have an impact on drinking behaviour. ${ }^{83}$ Web-based interventions allow employees to access the intervention anytime they want and in private to avoid disclosing a potential alcohol or illicit drug use problem. A meta-analysis of randomized clinical trials - that evaluated 82 separate computer-delivered health promotion interventions (CDI) - concluded that CDI can help individuals to make immediate post-intervention improvements in health-related knowledge attitudes, and intentions, as well as modifying health behaviours such as dietary intake, tobacco use, substance use, safer sexual behaviour, binge / purging behaviours, and general health maintenance. The evidence did not support the use of CDIs to improve physical activity, weight loss, or diabetes self-management.97 


\section{Employee assistance programmes}

Employee assistance programmes (EAPs) are worksite focused programmes which aim to assist in the identification and resolution of a broad range of employee concerns, which affect, or may affect, performance. With respect to alcohol and illicit drug use, EAPs focus on the assessment and identification of employees with problems, and their referral for appropriate treatment. Workers may refer themselves to an EAP, may be referred informally by the manager or by occupational health staff, or may be referred formally by their manager as part of a performance management process. Although EAPs are commonly used strategies to reduce alcohol and illicit drug problems in the workplace, these programmes are seldom evaluated, and little is known about their effectiveness ${ }^{83} \mathrm{~A}$ systematic review identified only three randomised control studies all from the US in which:

- one study found significant improvements on a number of outcomes for three different alcohol treatment conditions

- one study found no impact of enhanced follow up over treatment as usual for substance use clients

- one study found no difference between intervention and control groups following the introduction of a substance use programme..$^{98}$

The evidence from these heterogeneous studies is mixed and lack of replication means that they provide only limited evidence about the effectiveness of the EAP elements evaluated.

\subsection{Fitness for work}

The primary purpose of a medical assessment of fitness for work is to make sure that an individual is fit to perform the task involved effectively and without risk to their own or others' health and safety. It is not the intention to exclude the applicant from the job if at all possible, but to modify or adjust it as necessary to allow them to work efficiently and safely.9 Occupational health services provide information and advice to employees and employers regarding fitness for work and rehabilitation back to work, but few UK employees have access to an occupational health service. Since the GMC requires that doctors recognise and work within the limits of their competence, other practitioners must decide whether they are comfortable with advising about fitness for specific duties, or whether to refer a patient to another practitioner when this better serves the patient's needs. ${ }^{100}$

An employer can arrange modified work duties to support an employee's rehabilitation and return to normal work. In order to do so the employer will need to understand the nature and severity of the situation. All medical information about an employee is confidential and can only be disclosed to the employer with the informed consent of the employee. Care should be taken by health practitioners to disclose only such information that is necessary for this purpose. ${ }^{81}$ The information provided should be confined to non-medically confidential information such as functional capacity and workplace adjustments, (ie what the employee can and cannot do safely), that allow the employer to manage the issue and also discharge their own health and safety legal obligations.

Employees undergoing detoxification should not be employed in safety-critical roles, and in the meantime should normally be re-deployed temporarily to other work until they have successfully completed appropriate treatment. ${ }^{81}$ The choice of treatment/rehabilitation for an individual with an illicit drug or alcohol problem needs expert assessment, and is best arranged through the occupational health department or the treatment provider. ${ }^{87}$ Where a period of sickness absence is indicated and where employees co-operate with their treatment they should be supported with appropriate sickness absence benefits. ${ }^{81} \mathrm{~A}$ return to safety critical work involves the completion of appropriate treatment and in most cases; a period of monitoring that could include random and/or unannounced testing to detect any relapse of problems with alcohol or illicit drug use ${ }^{81,87}$ Urine and oral fluid testing may have a role within rehabilitation, pre- and post-return to duty, but with consideration that they reflect only recent exposure and the need for being unannounced to maintain the value of such testing. This may suggest an increased frequency of unannounced testing for that individual during an initial monitoring period of recommencing safety critical activities. Hair analysis may be a useful technique for employer and employee to prove drug abstinence over a longer time frame of weeks or months for return-to-duty testing and postreturn-to-duty testing. ${ }^{87}$

Blood Carbohydrate - deficient transferrin (CDT) is an alternative for detection and monitoring of increased consumption and progress towards abstinence and has a high diagnostic value to support diagnosis of alcohol-use disorders. ${ }^{88}$ The specificity of this marker in patient groups with liver disorders is superior to the biomarkers gamma-GT and MCV. ${ }^{89}$ 


\subsection{International perspectives}

The US transport regulatory model for rehabilitation and treatment in workers with a drug or alcohol violation involves the defined and accredited role of a 'Substance Abuse Professional'. This expert role, independent of employer or employee, is to define and ensure completion of an appropriate treatment regime for the individual before they can be returned to any safety critical work. The period of removal from safety critical activities for those with drug or alcohol violation according to the US regulations is not stipulated. The 'Substance Abuse Professional' also defines the necessary level of monitoring and assessment of the individual returning to such duties. ${ }^{87}$

\subsection{Summary}

- Since a significant proportion of adults who are at risk for problems with alcohol and illicit drug use are employed the workplace provides good opportunities for public health interventions

- The evidence for the impact of health promotion programmes at the workplace is limited

- Web-based approaches that include alcohol and illicit drugs as part of a general health promotion allow employees to access the intervention when they want, and in private, and have been shown to be effective

- Brief intervention approaches that involve personal assessment of an individual's drinking rates and related problems, as well as feedback about health risks, is likely to have the most potential

- Although EAPs are commonly used strategies to reduce problems with alcohol and illicit drug use in the workplace, these programmes are seldom evaluated, and little is known about their effectiveness

- The downfall to these approaches will occur eventually if the programmes are not sustained over time, and if obstacles (eg lack of organisational support and cooperation in implementing follow-up interventions) are not overcome ${ }^{53}$ 


\section{Chapter 9 - Occupational health support for job applicants}

In July 2015 Professor Dame Carol Black started a review into how best to support benefit claimants with addictions and potentially treatable conditions back into work. ${ }^{101}$ This chapter has been added to this report in response to that review.

For users not already in employment getting a stable job is a key step towards sustained recovery from substance dependence. ${ }^{102}$ However, most employers are reluctant to employ people with alcohol and drug problems, including those who have successfully completed rehabilitation. A survey of over 500 UK human resources professionals reported that in the previous two years only nine per cent of organisations had actively chosen to recruit individuals with previous alcohol problems, and only six per cent had chosen to recruit individuals with previous drug problems. ${ }^{9}$ Much stigma is attached to people who are, or have been in treatment for a drug or alcohol problem. While some employer perceptions of risk may be rooted in reality, many are fuelled by negative stereotypes. Yet the experiences of employers who recruit recovering substance users are often very positive, with low levels of absence and staff turnover and high levels of productivity. Such individuals can be much more motivated by work and grateful for the second chance the employer has provided them. ${ }^{103}$

\subsection{Abstinence periods}

Some laws and regulations mandate specific abstinence periods eg for driving. For roles not so regulated specified drug-free periods are entirely arbitrary and are of little use in determining an individual's suitability or readiness for employment. ${ }^{103,104,105}$ The most significant facilitator to future employment for problem drug users is receiving and completing a course of treatment; followed by training; voluntary work; and support to find work. ${ }^{106}$

\subsection{Post offer health assessments}

Post-offer health assessments are undertaken by specialist occupational health staff after a person has been offered a job and before he/she commences duties, usually in safety critical work, to ensure that any health condition from which the individual suffers does not present a hazard to themselves or to other persons, e.g. for airline pilots, air traffic control officers, armed forces personnel, seafarers, divers, licensed goods vehicle drivers, etc and to satisfy relevant legal requirements. ${ }^{107}$

When determining readiness to commence work it might be helpful for the occupational physician to obtain consent to obtain a medical report from a treatment provider to confirm that the individual is, in their view, stable and committed to rehabilitation. In other cases, volunteering or job placements can help to confirm ability to work. ${ }^{103}$ Chapter 5 of the DVLA Assessing Fitness to Drive defines requirements for alcohol or drug users or past users who will drive as an essential part of their job (Table 4). ${ }^{75}$ 
Table 4. Summary of DVLA requirements

\begin{tabular}{|c|c|c|}
\hline \multirow[t]{3}{*}{ Condition } & \multicolumn{2}{|c|}{ Minimum requirements } \\
\hline & \multicolumn{2}{|c|}{ Type of License } \\
\hline & Class 1 (car, motorcycle) & Class 2 (PCV. HGV) \\
\hline Alcohol misuse & $\begin{array}{l}\text { Six months controlled drinking } \\
\text { or abstinence }\end{array}$ & $\begin{array}{l}\text { One year controlled drinking or } \\
\text { abstinence }\end{array}$ \\
\hline Alcohol dependence & $\begin{array}{l}\text { One year free from alcohol } \\
\text { problems and abstinence } \\
\text { with normalisation of } \\
\text { blood parameters }\end{array}$ & 3 years abstinence \\
\hline Alcohol-related disorders & Satisfactory recovery & License refused \\
\hline Drug misuse and dependence & $\begin{array}{l}\text { Six to } 12 \text { months depending on } \\
\text { the drug used }\end{array}$ & $\begin{array}{l}\text { One to } 3 \text { years depending on the } \\
\text { drug used }\end{array}$ \\
\hline
\end{tabular}

Multiple substance misuse and/or dependence, including misuse with alcohol, is incompatible with licensing

\begin{tabular}{l|l|l}
\hline $\begin{array}{l}\text { Solitary alcohol-or drug-related } \\
\text { seizure }\end{array}$ & $\begin{array}{l}\text { Six months from the date of } \\
\text { the event }\end{array}$ & 5 years from the date of the event \\
\hline $\begin{array}{l}\text { Two or more alcohol-or drug- } \\
\text { related seizures }\end{array}$ & $\begin{array}{l}\text { One year free of seizures other } \\
\text { than a 'permitted seizure' }\end{array}$ & $\begin{array}{l}10 \text { years free of seizures and anti- } \\
\text { epileptic medication }\end{array}$ \\
\hline
\end{tabular}

It is the duty of the licence holder or licence applicant to notify DVLA of any medical condition, which may affect safe driving. On occasions however, there are circumstances in which the licence holder cannot, or will not do so. As noted in Chapter 5 the GMC provides clear guidelines applicable to such circumstances. 
In general, occupational physicians should consider the following when performing or reviewing a postoffer health assessment of a current or former drug or alcohol user:

- Time abstinent is not an indicator of competence

- Assessments should be considered on an individual basis and not by application of blanket policies

- People with experience of alcohol and drug misuse and alcohol and drug misuse treatment ${ }^{108}$

- On a practical level, clearly there are some instances where prescribed medicines can impair a person's ability to carry out a particular task but this should be factored in to any assessment of employment related needs

\subsection{Determining medical fitness for work}

- What are the essential duties of the task?

- What is the person's current and past history of alcohol or drug use?

- Will their current state of health, including any medication they are taking, present any current or foreseeable risk to the health and safety of themselves or others?

- Are there legal or regulatory requirements eg DVLA standards?

- Would a phased introduction to work be beneficial eg for someone who has been out of work for some time?

- Are there work or workplace factors that, if not managed, could aggravate their condition? For example high stress, long hours or irregular shift, fatigue, isolation, easy access to drugs or alcohol

- Is it appropriate to obtain with the patient's consent a report from a treatment provider?

\subsection{Monitoring}

Return to work can be stressful for anyone let alone someone who may feel stigmatised by having undergone rehabilitation for dependency. It will be helpful to review the job applicant in the occupational health department during their return to work in order to ensure that they are coping and that they have all of the necessary support. In some cases, and after careful consideration, it may be appropriate to discuss and agree individual monitoring with the applicant as part of that support in the workplace (see Chapter 7). It is important to explain to the individual that early detection of a recurrent problem may offer the best chance of successful medical intervention, and successful return to employment, and that monitoring is not seen to indicate any lack of trust by occupational health staff.

\subsection{Summary}

In supporting people with a past or current alcohol or drug problem back into work occupational staff must:

- Avoid the application of arbitrary abstinence periods

- Help employers understand how they can best support the person

- Help address employers' concerns about risks and challenge stigma and negative stereotypes

- Ensure that job applicants are aware of the employer's drug and alcohol workplace policy

- Ensure that job applicants understand what is expected of them and how to seek medical support if they experience problems 


\section{Other resources}

\section{BMA}

Alcohol

http://bma.org.uk/working-for-change/improving-and-protecting-health/alcohol

Cognitive enhancing drugs and the workplace

http://www.bma.org.uk/support-at-work/occupational-health/cognitive-enhancing-drugs

Drugs

http://www.bma.org.uk/working-for-change/improving-and-protecting-health/drugs-of-

dependence

Driving under the influence of drugs

http://bmaopac.hosted.exlibrisgroup.com/exlibris/aleph/a21_1/apache media/

R65SS6HJG36V8MJQ3768QHFKSRQK2P.pdf

The BMA exists to support its members in their professional lives. If you are a BMA member with an employment query contact our advisers, they are here to help you. Call 03001231233 between 08.30 to 18.00 Monday to Friday, excluding UK Bank Holidays.

\section{GMC}

Tomorrow's Doctors

http://www.gmc-uk.org/education/undergraduate/tomorrows doctors.asp

Good Medical Practice

http://www.gmc-uk.org/guidance/index.asp

Driver \& Vehicle Licensing Agency

https://www.gov.uk/government/organisations/driver-and-vehicle-licensing-agency

Health and Safety Executive

http://www.hse.gov.uk/alcoholdrugs/

Faculty of Occupational Medicine

http://www.fom.ac.uk/

NICE

NICE Pathways: Alcohol Use Disorders 


\section{References}

1 Nicholson PJ (2004) Occupational health services in the UK - challenges and opportunities. Occupational Medicine 54: 147-52.

2 General Medical Council (2015) Outcomes for graduates (Tomorrow’s doctors). London: General Medical Council.

3 Office for National Statistics (2016) Alcohol-related deaths in the United Kingdom, 2014. Newport: Office for National Statistics.

4 Office for National Statistics (2015) Deaths related to drug poisoning in England and Wales, 2014 registrations. September 2015. Newport: Office for National Statistics.

5 Office for National Statistics (2015) Overview of the UK Population. November 2015. Newport: Office for National Statistics.

6 Office for National Statistics (2016) UK Labour Market, June 2016. Newport: Office for National Statistics.

7 Health \& Safety Executive (1996) Don't mix it: a guide for employers on alcohol at work. Bootle: Health \& Safety Executive.

8 Health \& Safety Executive (2004) Drug misuse at work: a guide for employers. Bootle: Health \& Safety Executive.

9 Chartered Institute for Personnel Development. (2007) Managing drug and alcohol misuse at work. Survey report. September 2007. Chartered Institute for Personnel Development. London.

10 British Beer and Pub Association (2013) Statistical handbook 2013. London: British Beer and Pub Association.

11 Dunstan S (2012) General Lifestyle Survey overview. A report on the 2010 general lifestyle Survey. Newport: Office for National Statistics.

12 Home Office (2015) Drug misuse: findings from the 2014/15 crime survey for England and Wales. London: Home Office.

13 Health \& Safety Executive (2004) The scale and impact of illegal drug use by workers. Bootle: Health \& Safety Executive.

14 Office for National Statistics (2013) General Lifestyle Survey overview - a report on the 2011 General Lifestyle Survey. Newport: Office for National Statistics.

15 Office for National Statistics Statistical Bulletin (2016) Adult drinking habits in Great Britain, 2014. Newport: Office for National Statistics.

16 McManus S, Meltzer H, Brugha T et al (2009) Adult Psychiatric Morbidity in England, 2007. Results of a household survey. Leeds: The NHS Information Centre for Health and Social Care.

17 Scottish Government (2014) 2012/13 Scottish crime and justice survey: drug use. Edinburgh: Scottish Government Social Research.

18 Department for Health Social Security and Public Safety (2015) Drug use in Ireland and Northern Ireland drug prevalence survey 2014/15. Belfast: Department for Health Social Security and Public Safety.

19 Norwich Union Healthcare press release (7.5.08) UK employees admit that regular drinking affects their jobs.

20 PruHealth press release (30.11.06) 200,000 Hungover workers on any given day. Effects of 'Booze Britain' hit the workplace.

21 York Health Economics Consortium, University of York (2010) The societal cost of alcohol misuse in Scotland for 2007. Edinburgh: The Scottish Government.

22 Ramsay M, Barker P, Goulden C et al (2001) Drug misuse declared in 2000: results from the British Crime Survey. London: Home Office Research, Development and Statistics Directorate.

23 UK Drug Policy Commission. Representations of drug use and drug users in the British press. (2010). London. UK Drug Policy Commission.

24 Larson SL, Eyerman J, Foster MS et al (2007) Worker substance use and workplace policies and programs (DHHS Publication No. SMA 07-4273, Analytic Series A-29). Rockville, MD: Substance Abuse and Mental Health Services Administration, Office of Applied Studies.

25 Substance Abuse and Mental Health Services Administration (2014) Results from the 2013 National Survey on drug use and health: summary of national findings, NSDUH Series H-46, HHS Publication No. (SMA) 14-4863. Rockville, MD: Substance Abuse and Mental Health Services Administration.

26 Ministry of Health (2010). Key Results of the 2007/08 New Zealand Alcohol and Drug Use Survey. Wellington. Ministry of Health

27 Australian Institute of Health and Welfare (2014). National drug strategy household survey detailed report 2013. Drud statistic series no 28. PHE 183. Canberra. Australian Institute of Health and Welfare. 
28 Pidd K, Berry JG, Harrison JE et al (2006) Alcohol and work: patterns of use, workplace culture \& safety. Adelaide: Australian Institute of Health and Welfare.

29 Pidd K, Shtangey V \& Roche AM (2008) Alcohol use in the Australian workforce: prevalence, patterns, and implications: findings from a secondary analysis of 2004 NDSHS data. Adelaide: National Centre for Education and Training on Addiction, Flinders University.

30 Breugem L, Barnett L, Cormack S et al (2006) The impact of alcohol \& other drugs in the workplace. Final project report 2006. Adelaide: SafeWork SA and Drug and Alcohol Services South Australia.

31 Brown D \& Bowden Jones D (2013) Drugs and alcohol in the workplace. In: Palmer KT, Brown I \& Hobson J (eds) Fitness for work. Oxford: Oxford University Press.

32 Department of Health (2016). Alcohol Guidelines Review - Report from the Guidelines development group to the UK Chief Medical Officers. January 2016. London. Department of Health.

33 Room R, Babor T \& Rehm J (2005) Alcohol and public health. The Lancet 365: 519-30.

34 British Medical Association (2008) Alcohol misuse: tackling the UK epidemic. London: British Medical Association.

35 British Medical Association (2013) Drugs of dependence - the role of medical professionals. London: British Medical Association.

36 Holtermann S \& Burchell A (1981) Government economic service working party. No 37. London: Department of Health and Social Security.

37 Leontaridi R (2003) Alcohol misuse: how much does it cost? London: Cabinet Office.

38 National Institute for Health and Clinical Excellence (2010) Alcohol-use disorders: preventing harmful drinking. Costing report. London: National Institute for Health and Clinical Excellence.

39 Roberts M (2004) Drug testing in the workplace. The Report of the independent inquiry into drug testing at work. York: Joseph Rowntree Foundation.

40 Department of Health. Written evidence to the Health Select Committee GAS01 (19 July 2012).

41 Lister G (2007) Evaluating social marketing for health - the need for consensus. Proceedings of the National Social Marketing Centre, 24-25 September, Oxford.

42 Johnston MC, Ludbrook A \& Jaffray MA (2012) Inequalities in the distribution of the costs of alcohol misuse in Scotland: a cost of illness study. Alcohol and Alcoholism 47: 725-31.

43 Hay G \& Bauld L (2008) Population estimates of problematic drug users in England who access DWP benefits: a feasibility study. DWP Working Paper No. 46. London: Department for Work and Pensions.

44 Hay G \& Bauld L (2010) Population estimates of alcohol misusers who access DWP benefits. DWP Working Paper.No. 94. London: Department for Work and Pensions.

45 Casey J, Hay G, Godfrey C et al (2009) Assessing the scale and impact of illicit drug markets in Scotland. Edinburgh: The Scottish Government.

46 Confronting substance abuse in small business. Proceedings of the National Conference sponsored by US Department of Labor, the Small Business Administration and the Office of National Drug Control Policy, (1992) Washington DC.

47 European Alcohol and Health Forum (2011) Alcohol, work and productivity. Scientific opinion of the science group of the European alcohol and health forum. Brussels: European Alcohol and Health Forum.

48 Johansson E, Böckerman P \& Uutela A (2009) Alcohol consumption and sickness absence: evidence from microdata. European Journal of Public Health 19:19-22.

49 Anderson P, Møller L \& Galea G (2012) Alcohol in the European Union. Consumption, harm and policy approaches. Copenhagen: WHO Regional Office for Europe.

50 Rehm J, Baliunas D, Brochu Set al (2006) The costs of substance abuse in Canada 2002. Ottawa, ON: Canadian Centre on Substance Abuse. Alcohol, drugs and the workplace - The role of medical professionals 32

51 Collins DJ \& Lapsley HM (2008) The costs of tobacco, alcohol and illicit drug abuse to Australian society in 2004/05. Canberra: Australian Government Department of Health \& Ageing.

52 National workshop on alcohol policy: health perspectives. Proceedings of the All India Institutes of Medical Sciences, 25-26 September 1997, New Delhi.

53 Ames GM \& Bennett JB (2011) Prevention interventions of alcohol problems in the workplace. A review and guiding framework. Alcohol Research \& Health 34: 175-9.

54 Roche AM, Pidd K, Berry JG et al (2008) Workers' drinking patterns: the impact on absenteeism in the Australian workplace. Addiction 103:738-48.

55 National Occupational Health and Safety Commission (1999) Work-related traumatic fatalities in south Australia, 1989-1992. Canberra: National Occupational Health and Safety Commission.

56 World Health Organization (2004) WHO global status report on alcohol 2004. Geneva: Department of Mental Health and Substance Abuse, World Health Organization. 
57 Norström T (2006) Per capita alcohol consumption and sickness absence. Addiction 101: 1421-7.

58 Norström T \& Moan IM (2009) Per capita alcohol consumption and sickness absence in Norway. European Journal of Public Health 19: 383-8.

59 Galea S \& Ghodse H (2005) Drug misuse and the work culture. In: Addiction at work: tackling drug use and misuse in the workplace. Ghodse $\mathrm{H}$ (eds). Aldershot: Gower Publishing Ltd.

60 Lucas G (2005) Effects and risks of workplace culture In: Addiction at work: tackling drug use and misuse in the workplace. Ghodse H (eds). Aldershot: Gower Publishing Ltd

61 Coggon D, Harris EC, Brown T et al (2009) Occupational mortality in England and Wales, 1991-2000. London: Office for National Statistics.

62 Romeri E, Baker A \& Griffiths C (2007) Alcohol-related deaths by occupation, England and Wales, 2001-05. Health Statistics Quarterly 35: 6-12.

63 Head J, Stansfeld SA \& Siegrist J (2004) The psychosocial work environment and alcohol dependence: a prospective study. Journal of Occupational and Environmental Medicine 61:219-24.

64 Larson S L, Eyerman J, Foster M S et al (2007) Worker substance use and workplace policies and programs (DHHS Publication No. SMA 07-4273, Analytic Series A-29). Rockville, MD: Substance Abuse and Mental Health Services Administration, Office of Applied Studies.

65 Hemström O (2002) Alcohol-related deaths contribute to socioeconomic differentials in mortality in Sweden. European Journal of Public Health 12: 254-62.

66 Hemmingsson T, Ringbäck \& Weitoft G (2001) Alcohol-related hospital utilization and mortality in different occupations in Sweden in 1991-1995. Scandinavian Journal of Work, Environment and Health 27: 412-9.

67 Virtanen M, Jokela M, Nyberg ST, et al (2015) Long working hours and alcohol use: systematic review and meta-analysis of published studies and unpublished individual participant data British Medical Journal; 350 :g7772.

68 Health \& Safety Executive (2003) Driving at work: managing work-related road safety. Bootle: Health \& Safety Executive.

69 Carter T (2006) Fitness to drive - a guide for health professionals. London: Department for Transport.

70 British Medical Association (1990) BMA guide to living with risk. London: British Medical Association.

71 Roberts S \& Marlow P (2005) Traumatic work related mortality among seafarers employed in British merchant shipping 1976 2002. Occupational and Environmental Medicine 62: 172-80.

72 Slovic P (1987) Perception of risk. Science 236: 280-5.

73 British Medical Association (2012) Risk: what's your perspective. London: British Medical Association.

74 Department for Transport (2015) Reported Road Casualties Great Britain: 2014 . Annual Report. Moving Britain Ahead. 4th September 2015. London. Department for Transport.

75 Driving and Vehicle Licensing Agency (2016). Assessing fitness to drive - a guide for medical professionals. Swansea: Driving and Vehicle Licensing Agency.

76 General Medical Council (2009) Good medical practice: confidentiality. London: General Medical Council.

77 General Medical Council (2009) Confidentiality: reporting concerns about patients to the DVLA or DVA. London: General Medical Council.

78 British Medical Association (2009) Driving under the influence of drugs London: British Medical Association.

79 Girotto E, Eumann Mesas A, de Andrade SM et al (2014) Psychoactive substance use by truck drivers: a systematic review. Occupational and Environmental Medicine 71: 71-6.

80 International Labour Office (1996) Alcohol- and drug-related issues in the workplace. Geneva: International Labour Office.

81 Faculty of Occupational Medicine, Royal College of Physicians of London (2006) Guidance on alcohol and drug misuse in the workplace. London: Faculty of Occupational Medicine.

82 van der Molen HF, Lehtola MM, Lappalainen J et al (2007) Interventions for preventing injuries in the construction industry. Cochrane Database of Systematic Reviews: CD006251.

83 Cercarelli R, Allsop S, Evans M et al (2012) Reducing alcohol-related harm in the workplace (an evidence review: full report). Melbourne: Victorian Health Promotion Foundation.

84 Parliamentary Office of Science and Technology (2004) Drug tests. London: Parliamentary Office of Science and Technology.

85 Faculty of Occupational Medicine, Royal College of Physicians (2012) Ethics guidance for occupational health practice. London: Faculty of Occupational Medicine.

86 Information Commissioner's Office (2011) The employment practices code. Wilmslow: Information Commissioner's Office. 
87 Akrill P \& Mason H (2004) Review of drug testing methodologies (T133) HE 04 / 04. London: Rail Safety and Standards Board.

88 Sharpe PC (2001) Biochemical detection and monitoring of alcohol abuse and abstinence. Ann Clin Biochem 38 652-664.

89 Hock B, Schwarz M, Domke I, et al (2005) Validity of carbohydrate-deficient transferrin (\%CDT), gammaglutamyltransferase (gamma-GT) and mean corpuscular erythrocyte volume (MCV) as biomarkers for chronic alcohol abuse: a study in patients with alcohol dependence and liver disorders of non-alcoholic and alcoholic origin. Addiction 100:1477-86

90 San Francisco Chronicle (12.8.01) The drug testing industry is a multibillion dollar profit center.

91 Flynn G (1999) How to prescribe drug testing. Workforce 78: 107-9.

92 Cashman CM, Ruotsalainen JH, Greiner BA et al (2009) Alcohol and drug screening of occupational drivers for preventing injury. Cochrane Database of Systematic Reviews:CD006566.

93 Kuoppala J, Lamminpää A \& Husman P (2008) Work health promotion, job well-being, and sickness absences a systematic review and meta-analysis. Journal of Occupational and Environmental Medicine 11: 1216-27.

94 Osilla KC, Van Busum K, Schnyer C et al (2012) Systematic review of the impact of worksite wellness programs. American Journal of Managed Care 18: e68-81.

95 Hermansson U, Helander A, Brandt L et al (2010) Screening and brief intervention for risky alcohol consumption in the workplace: results of a 1-year randomized controlled study. Alcohol and Alcoholism 45: 252-7.

96 National Institute for Health and Clinical Excellence (2007) Drug misuse: psychosocial interventions. London: National Institute for Health and Clinical Excellence.

97 Portnoy DB, Scott-Sheldon LA, Johnson BT et al (2008) Computer-delivered interventions for health promotion and behavioral risk reduction: a meta-analysis of 75 randomized controlled trials, 19882007. Preventive Medicine 47: 3-16.

98 Rick J, Carroll C, McGregor M et al (2012) Systematic review of the effectiveness and cost effectiveness of employee assistance programmes. Systematic review final report. Sheffield: Institute of Work Psychology, University of Sheffield.

99 Palmer KT \& Brown I (2013) A general framework for assessing fitness for work. In: Palmer KT, Brown I \& Hobson J (eds) Fitness for work. Oxford: Oxford University Press.

100 General Medical Council (2013) Good medical practice. London: General Medical Council.

101 Department for Work and Pensions (2015). An independent review into the impact on employment outcomes of drug or alcohol addiction, and obesity: call for evidence. London. Department for Work and Pensions.

102 Klee H, McLean I, Yavorsky C. (2002), 'Employing drug users: Individual and systemic barriers to rehabilitation,' Work and Opportunity Series; No. 29. York: Joseph Rowntree Foundation.

103 Singleton N \& Lynam B. The other half of the equation: employers' readiness to recruit problem drug users. Drug and Alcohol Today. 2009, 9; 1: 7-12

104 UK Drug Policy Commission (2008). Working towards recovery; getting problem drug users into jobs. London. UK Drug Policy Commission.

105 National Treatment Agency for Substance Misuse (2010). Two year rule note. London. National Treatment Agency for Substance Misuse.

106 Bauld L, Hay G, McKell J, Carroll K, McKell J, Novak K, Silver K, et al. Problem drug users' experiences of employment and the benefit system. (2010). Research Report No 640. Department for Work and Pensions. Norwich. HM Stationery Office.

107 British Medical Association (2106). The occupational physician. London. British Medical Association.

108 Chartered Institute for Personnel Development. (2007). Managing drug and alcohol misuse at work. A guide for people management professionals. Chartered Institute for Personnel Development London. 

British Medical Association, BMA House, Tavistock Square, London WC1H 9JP bma.org.uk 